\title{
Androgen excess in pancreatic $\beta$ cells and neurons predisposes female mice to type 2 diabetes
}

Guadalupe Navarro, ${ }^{1}$ Camille Allard, ${ }^{2}$ Jamie J. Morford, ${ }^{2}$ Weiwei Xu, ${ }^{2}$ Suhuan Liu, ${ }^{1}$ Adrien J.R. Molinas, ${ }^{3}$ Sierra M. Butcher, ${ }^{3}$ Nicholas H.F. Fine, ${ }^{4,5}$ Manuel Blandino-Rosano, ${ }^{6}$ Venkata N. Sure, ${ }^{7}$ Sangho Yu, ${ }^{8}$ Rui Zhang, ${ }^{8}$ Heike Münzberg, ${ }^{8}$ David A. Jacobson, ${ }^{9}$ Prasad V. Katakam, ${ }^{7}$ David J. Hodson, ${ }^{4,5}$ Ernesto Bernal-Mizrachi, ${ }^{6}$ Andrea Zsombok, ${ }^{3}$ and Franck Mauvais-Jarvis ${ }^{2,3,10,11}$

'Department of Medicine, Division of Endocrinology, Metabolism and Molecular Medicine, Northwestern University, Feinberg School of Medicine, Chicago, Illinois, USA. ${ }^{2}$ Department of Medicine, Section of Endocrinology and Metabolism, and ${ }^{3}$ Department of Physiology, Tulane University Health Sciences Center, School of Medicine, New Orleans, Louisiana, USA. ${ }^{4}$ Institute of Metabolism and Systems Research, University of Birmingham, Edgbaston, United Kingdom. ${ }^{5}$ Centre for Endocrinology, Diabetes and Metabolism, Birmingham Health Partners, Birmingham, United Kingdom. ${ }^{6}$ Department of Internal Medicine, Division Endocrinology, Metabolism and Diabetes, Miller School of Medicine, University of Miami, Miami, Florida, USA. 'Department of Pharmacology, Tulane University Health Sciences Center, School of Medicine, New Orleans, Louisiana, USA. ${ }^{8}$ Department of Neurobiology of Nutrition and Metabolism, Pennington Biomedical Research Center, Louisiana State University System, Baton Rouge, Louisiana, USA. ${ }^{9}$ Department of Molecular Physiology and Biophysics, Vanderbilt University, Nashville, Tennessee, USA. ${ }^{10}$ Tulane Brain Institute and "Southeast Louisiana Veterans Healthcare System, New Orleans, Louisiana, USA.

Androgen excess predisposes women to type 2 diabetes (T2D), but the mechanism of this is poorly understood. We report that female mice fed a Western diet and exposed to chronic androgen excess using dihydrotestosterone (DHT) exhibit hyperinsulinemia and insulin resistance associated with secondary pancreatic $\beta$ cell failure, leading to hyperglycemia. These abnormalities are not observed in mice lacking the androgen receptor (AR) in $\beta$ cells and partially in neurons of the mediobasal hypothalamus (MBH) as well as in mice lacking AR selectively in neurons. Accordingly, i.c.v. infusion of DHT produces hyperinsulinemia and insulin resistance in female WT mice. We observe that acute DHT produces insulin hypersecretion in response to glucose in cultured female mouse and human pancreatic islets in an AR-dependent manner via a cAMP- and mTOR-dependent pathway. Acute DHT exposure increases mitochondrial respiration and oxygen consumption in female cultured islets. As a result, chronic DHT exposure in vivo promotes islet oxidative damage and susceptibility to additional stress induced by streptozotocin via AR in $\beta$ cells. This study suggests that excess androgen predisposes female mice to T2D following AR activation in neurons, producing peripheral insulin resistance, and in pancreatic $\beta$ cells, promoting insulin hypersecretion, oxidative injury, and secondary $\beta$ cell failure.

Conflict of interest: The authors have declared that no conflict of interest exists.

Submitted: February 26, 2018 Accepted: May 10, 2018 Published: June 21, 2018

\section{Reference information:} JCI Insight. 2018;3(12):e98607 https://doi.org/10.1172/jici. insight.98607.

\section{Introduction}

The association between testosterone (androgen) excess and dysglycemia in women has been known since the original description of diabetes in bearded women by Achard and Thiers (1). In most prospective and cross-sectional studies, increased testosterone concentrations are associated with increased risk of type 2 diabetes (T2D) in women (2), and polycystic ovarian syndrome (PCOS), the main cause of testosterone excess, predisposes women to T2D (3-5). Despite this background, the exact mechanism of hyperglycemia in women with androgen excess is unknown. In extreme syndromes of insulin resistance and in obese women with PCOS, insulin resistance and the resulting hyperinsulinemia drive the ovarian production of androgens (6). However, extensive evidence suggests that in the most common form of PCOS androgen excess is instrumental in altering glucose homeostasis. First, PCOS is characterized by primary functional 
ovarian hyperandrogenism that is independent from insulin resistance (7). Second, in hyperandrogenic women, about half of the intervention studies to reduce androgen levels or block androgen action improved insulin sensitivity and glucose homeostasis (8-12). Finally, testosterone administration to healthy women or female-to-male transsexuals also promotes insulin resistance $(13,14)$. Therefore, it is critical to dissect the mechanisms by which androgen excess alters glucose homeostasis in women using preclinical models because it opens new avenues for therapy.

Male mice with neuronal androgen receptor (AR) deletion exhibit hypothalamic insulin resistance, demonstrating the importance of AR action in the brain in promoting insulin sensitivity (15). In female mice, testosterone alters kisspeptin and gonadotropin-releasing hormone neuronal function in the arcuate nucleus (ARC) of the hypothalamus (16), an area that controls peripheral insulin sensitivity (17-21). We reported that developmental or adult androgen excess in female mice alters the function of ARC neurons in an AR-dependent manner $(22,23)$. Thus, testosterone action in hypothalamic neurons could contribute to insulin resistance in hyperandrogenic women $(24,25)$.

It is widely recognized that pancreatic $\beta$ cell failure is essential to the pathogenesis of diabetes $(26,27)$, suggesting that hyperglycemic women with androgen excess exhibit $\beta$ cell dysfunction. In fact, women with androgen excess exhibit either higher basal insulin secretion and decreased postprandial insulin secretion (28) or an exaggerated acute insulin response to glucose (29). These abnormalities are not explained by insulin resistance and are closely associated with androgen excess (30). In these women, there is a robust relationship between $\beta$ cell function and testosterone, raising the possibility that excess testosterone produces insulin hypersecretion and $\beta$ cell dysfunction (31). The AR is expressed in $\beta$ cells in both sexes, and AR activation in $\beta$ cells enhances glucose-stimulated insulin secretion (GSIS) from male rodent and human islets (32). Thus, in women, testosterone action on the $\beta$ cell AR may produce insulin hypersecretion and $\beta$ cell dysfunction.

To explore the hypothesis that androgen excess produces T2D via action on AR in $\beta$ cells and/or neurons, we generated female mice with androgen excess and conditional AR deletion in $\beta$ cells and/or neurons. We show that androgen excess predisposes these mice to hyperglycemia via the combined activation of the AR in pancreatic $\beta$ cells (producing dysfunction) and hypothalamic neurons (producing peripheral insulin resistance).

\section{Results}

Generation of female mice with $A R$ deletion in $\beta$ cells and hypothalamus. We previously reported that male $\beta$ cell-specific AR-knockout ( $\beta \mathrm{ARKO}^{\mathrm{RIP}}$ ) mice, generated using a RIP2-Cre transgene, exhibit total $\beta$ cell AR elimination associated with a 50\% elimination of $\mathrm{AR}$ in the ARC and ventromedial hypothalamus $(\mathrm{VMH})(32)$. Therefore, we used this model to assess the effect of androgen excess in $\beta$ cells and hypothalamic neurons of female mice. Since mice expressing the RIP2-Cre transgene develop glucose intolerance and impaired insulin secretion even in the absence of genes targeted by loxP sites (33), we have used the RIP-Cre mice as a control group in female as well as in male mice (32). Elimination of the AR protein in islets (Figure 1A) and decreased AR expression in the ARC (Figure 1, B and C) and VMH (Figure 1, B and D) was confirmed in female $\beta A R K O^{\text {RIP }}$ mice.

Androgen excess predisposes female controls, but not $\beta A R K O^{R I P}$ mice, to diabetes. To study the metabolic consequences of androgen excess in vivo, female control and $\beta A R K O^{\mathrm{RIP}}$ mice were exposed to dihydrotestosterone (DHT) - the nonaromatizable AR agonist — or vehicle for 4 weeks (vehicle, $121.5 \pm 12 \mathrm{pg} / \mathrm{ml}$, DHT $489 \pm$ $23.2 \mathrm{pg} / \mathrm{ml}$, mean $\pm \mathrm{SEM}$ ). On a normal chow diet, female $\beta A R K \mathrm{~S}^{\mathrm{RIP}}$ mice showed no alteration in glucose homeostasis compared with controls (Supplemental Figure 1, A-G; supplemental material available online with this article; https://doi.org/10.1172/jci.insight.98607DS1). Following exposure to DHT, both control and $\beta A R K O^{\text {RIP }}$ mice retained normal glucose tolerance (Supplemental Figure 1A) and normal fasting and fed blood glucose levels (Supplemental Figure 1, B and C) and fasting insulin levels (Supplemental Figure 1D). However, DHT exposure produced a marked fed hyperinsulinemia in control mice, which was not observed in $\beta A R K O^{R I P}$ mice (Supplemental Figure 1E). Control and $\beta A R K O{ }^{R I P}$ mice treated with vehicle and DHT retained similar islet architecture and pancreatic insulin concentration (Supplemental Figure 1, F and G). Exposure to DHT slightly increased $\beta$ cell mass in both control and $\beta A_{R K O}{ }^{R I P}$ mice (Supplemental Figure $1 F$ ).

To mimic metabolic stress seen in humans, mice were exposed to a high-sucrose, high-fat Western diet (WD). Under these conditions, exposure to DHT produced abnormalities characteristic of early T2D in female control mice. They displayed fasting and fed hyperinsulinemia (Figure 2, A and B) associated with exaggerated GSIS (Figure 2C) and insulin resistance during an insulin tolerance test (ITT) (Figure 2D). Accordingly, these mice developed compensatory $\beta$ cell hyperplasia, with increased islet size and $\beta$ cell mass as well as pancreas insulin content (Figure 2, E-G). However, DHT exposure produced a failure of 
A
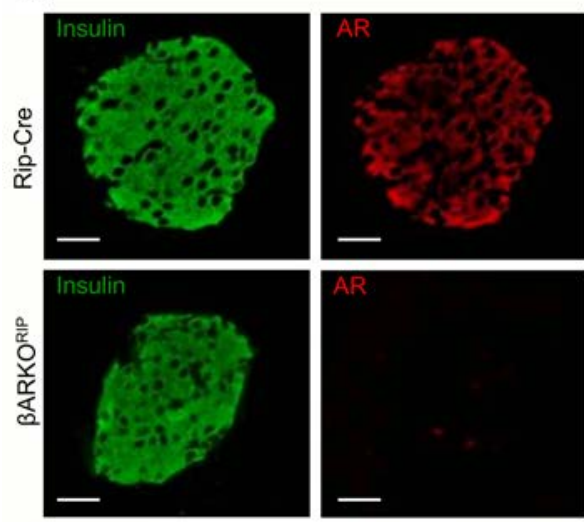

B
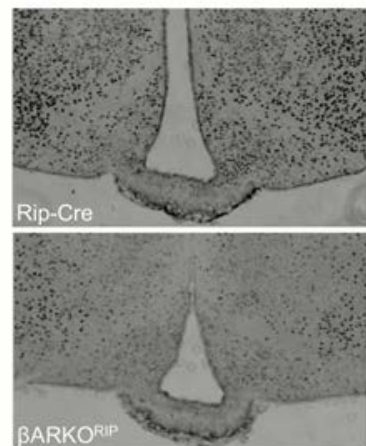

C

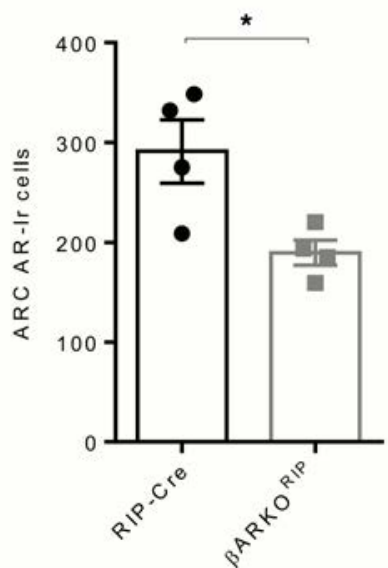

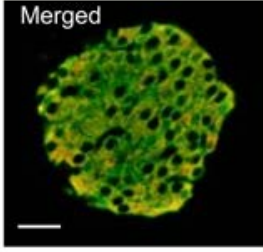

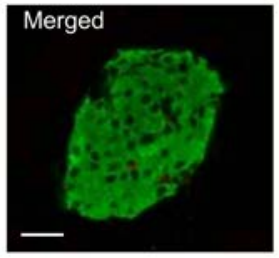

D

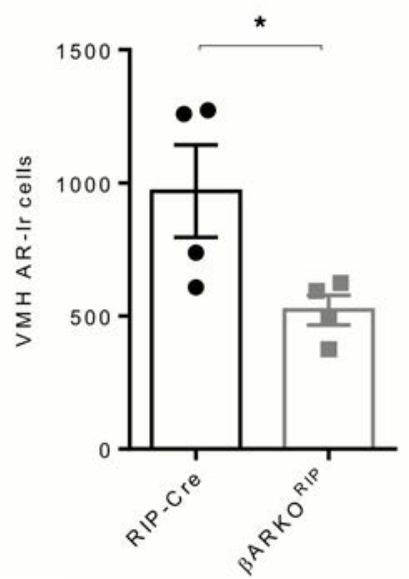

Figure 1. AR expression in pancreatic $\boldsymbol{\beta}$ cells and the hypothalamus of $\beta A R K O^{\text {RIP }}$ female mice. (A) Pancreas sections showing AR immunofluorescent staining (red) colocalizing with insulin (green) in $\beta$ cells of control RIP-Cre female mice and confirming successful AR deletion in representative $\beta A R K O^{\mathrm{RIP}}$ islets at 12 weeks. Original magnification, $\times 40$. (B) AR expression in the arcuate nucleus (ARC) and ventromedial hypothalamus (VMH) of RIP-Cre and $\beta A R K 0^{\text {RIP }}$ mice, as assessed by immunostaining. (C) AR-immunoreactive cell number in the ARC. (D) AR-immunoreactive cell number in the VMH. Values represent the mean \pm SEM with dot plots $(n=4)$. ${ }^{*} P<0.05$, Student's $t$ test.

$\beta$ cells to compensate for insulin resistance, as DHT-exposed control mice exhibited hyperglycemia in the fasting and fed state despite hyperinsulinemia (Figure 2, H and I) and following a glucose challenge (Figure 2J). In control mice, DHT exposure was also associated with increased expression of PEPCK (pck1) mRNA in liver, suggesting increased gluconeogenesis (Figure $2 \mathrm{~K}$ ). In contrast, in female $\beta A R K{ }^{\text {RIP }}$ mice, exposure to DHT did not produce fasting hyperinsulinemia and did not induce insulin resistance with associated $\beta$ cell hyperplasia (Figure $2, A-G$ ). These mice remained normoglycemic in the fasting and fed states and during a glucose challenge (Figure 2, H-J), and DHT produced no increase in liver PEPCK mRNA (Figure $2 \mathrm{~K}$ ). Thus, under the conditions of a WD, chronic DHT exposure has produced a phenotype of insulin resistance with islet hyperplasia and hyperinsulinemia, culminating in hyperglycemia in control mice. This is not observed in $\beta A R K O^{\text {RIP }}$ mice on WD exposed to chronic DHT.

Androgen excess predisposes female controls, but not $\mathrm{NARKO}^{--}$mice, to diabetes. In female mice, AR protein was expressed in the ARC and the VMH (Figure 3, A and B). Expression of AR protein in these nuclei was similar in males and females (Figure 3, C and D). Likewise, in microdissected ARC, $A R$ mRNA expression was similarly expressed in female and male mice (Figure $3 \mathrm{E}$ ). Consistent with the functionality of AR in female neurons of the mediobasal hypothalamus $(\mathrm{MBH})$, whole-cell patch-clamp recordings were conducted to determine the effect of DHT application on the excitability of neurons in the ARC and VMH. In the ARC, application of DHT altered the firing rate in a subset of recorded neurons (Figure 3, F-H and L, and Supplemental Table 1). Following DHT application, hyperpolarization was observed in 7 of 19 recorded 
A
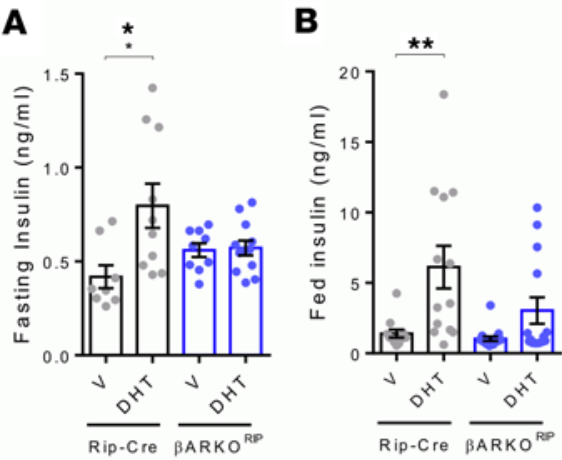

\section{D}
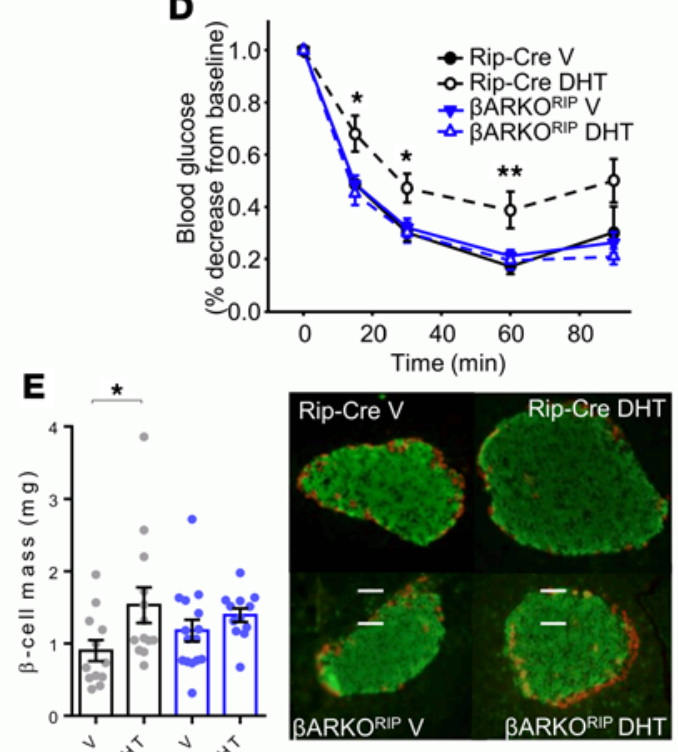

$$
\text { H }
$$
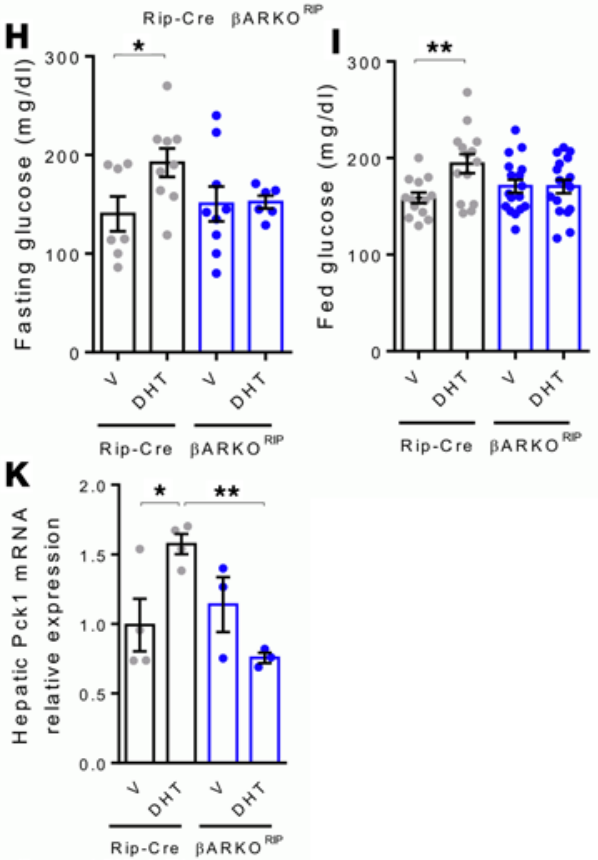

C
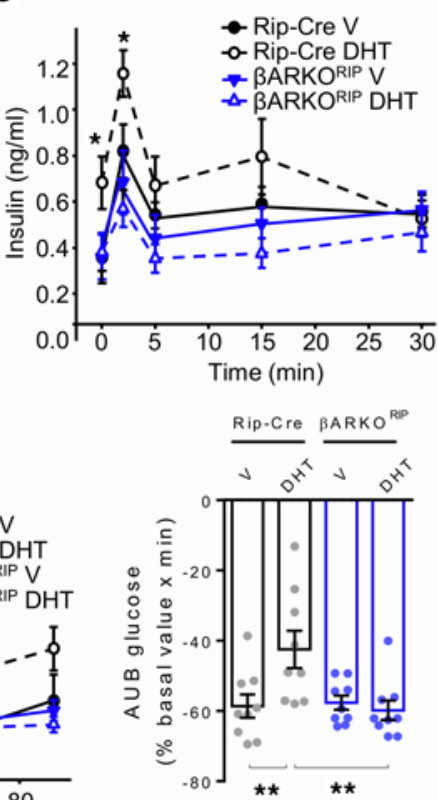
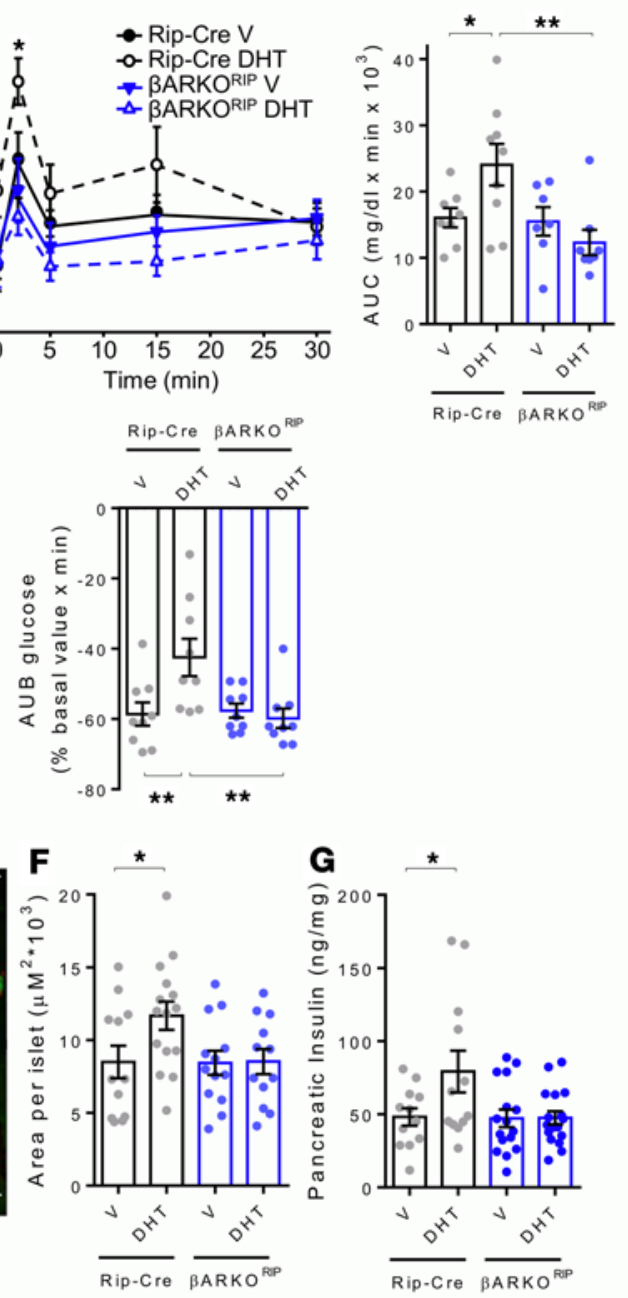

Rip-Cre $\overline{\text { BARKO }}$

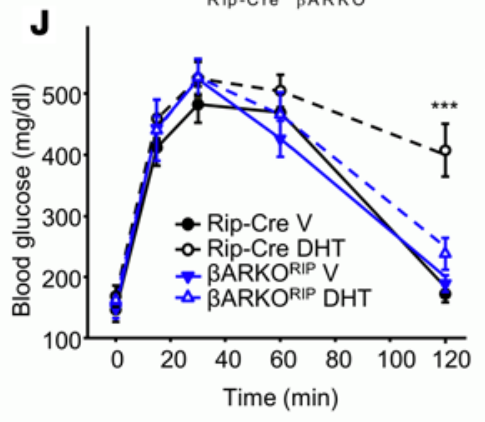

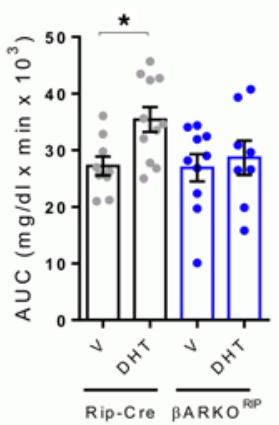

Figure 2. Chronic DHT excess predisposes female controls, but not BARKO $^{\text {RIP mice, to dia- }}$ betes. Female mice were fed WD for 9 weeks followed by s.c. treatment with vehicle (V) or DHT for 4 weeks. (A) Fasting serum insulin levels.

(B) Random fed serum insulin levels. (C) Insulin secretion during an i.p. glucose-stimulated insulin secretion (CSIS) test $(3 \mathrm{~g} / \mathrm{kg}$ ) and corresponding AUC. (D) i.p. insulin tolerance test (ITT) with blood glucose represented as percentage decrease from baseline, with corresponding area under baseline (AUB).

(E) $\beta$ Cell mass and representative islets with insulin staining (green) Scale bar: $10 \mu \mathrm{m}$. (F) Islet area. (C) Pancreas insulin concentration. (H) Fasting blood glucose. (I) Random fed blood glucose. (J) Blood glucose during an i.p. glucose tolerance test (GTT) (2 g/ $\mathrm{kg}$ ) and AUC. (K) Hepatic pck1 relative expression quantified by qPCR. Values represent the mean \pm SEM with dot plots $(n$ $=6-19) .{ }^{*} P<0.05,{ }^{* *} P<$ 0.01 , Student's $t$ test or 2-way ANOVA. 
neurons, accompanied by a decrease in action potential frequency (Figure 3, F-H and L, and Supplemental Table 1). In contrast, another subset of neurons responded with depolarization and an increase in firing rate, which did not reach statistical significance (Figure 3, I-K, and Supplemental Table 1). The remainder of the recorded neurons was unresponsive to DHT $(-42.93 \pm 3.56 \mathrm{mV}$ vs. $-41.98 \pm 3.65 \mathrm{mV}, n=8)$. In the $\mathrm{VMH}$, bath application of DHT showed similar results. A decrease in action potential frequency was determined in 6 of 10 recorded VMH neurons $(2.44 \pm 0.65 \mathrm{~Hz}$ vs. $1.05 \pm 0.38 \mathrm{~Hz})(P<0.05)$, while two neurons responded with an increasing trend $(1.35 \pm 0.62 \mathrm{~Hz}$ vs. $4.27 \pm 0.38 \mathrm{~Hz})$ and two did not respond to DHT $(5.30 \pm 1.61 \mathrm{~Hz}$ to $5.23 \pm 2.05 \mathrm{~Hz})$ (Figure $3 \mathrm{~L}$ and Supplemental Table 1$)$.

To assess the contribution of AR in the hypothalamus to DHT-induced insulin resistance and hyperglycemia, we generated female neuronal AR-knockout $\left(\mathrm{NARKO}^{-/-}\right)$mice by crossing $\mathrm{AR}^{\text {lox/lox }}$ mice with the synapsin-Cre-transgenic mice. $\mathrm{NARKO}^{-/-}$male mice have previously been shown to display decreased AR expression in the brain but normal expression in other tissues (32). In female $\mathrm{NARKO}^{-/-}$mice, body weight, fasting and fed blood glucose and insulin, glucose tolerance, insulin sensitivity, and GSIS were similar to those of control $\mathrm{AR}^{\mathrm{lox} / \mathrm{lox}}$ mice on a normal chow diet (Supplemental Figure 2). Consistent with results obtained previously (Figure 2), DHT exposure in WD-fed female control mice produced fasting and fed hyperinsulinemia with insulin resistance (Figure 4, A-C) associated with hyperglycemia in the fasting and fed states (Figure 4, D and E) and during glucose challenge (Figure $4 \mathrm{~F}$ ). These effects were not observed in female $\mathrm{NARKO}^{-/}$mice (Figure 4). This demonstrates that excess DHT action on neuronal AR is instrumental to the diabetogenic effect of DHT in female mice. Note that DHT exposure produced an increase in body weight and adipose tissue mass in female control mice fed a WD, which was not observed in female $\mathrm{NARKO}^{-/-}$mice (Supplemental Figure 3).

To further characterize the contribution of excess AR activation in neurons to hyperglycemia in female mice exposed to a WD, we infused DHT directly into the lateral ventricle of the brain in order to induce central DHT excess without peripheral DHT elevation. We confirmed that serum DHT concentrations were not increased in DHT-infused mice (vehicle, $162.6 \pm 14.3$; DHT, $171.5 \pm 24.3 \mathrm{pg} / \mathrm{ml}$ ). After 4 weeks of infusion, compared with vehicle-infused female mice, DHT-infused mice developed isolated fasting hyperinsulinemia (Figure 5, A and B) associated with insulin resistance during ITT (Figure 5C). Unlike those after peripheral exposure to DHT, central DHT had no effect on fed and fasted blood glucose and glucose tolerance (Figure 5, D-F). In addition, central DHT infusion had no effect on body weight and adipose tissue mass (Supplemental Figure 4). These findings confirm that excess AR activation selectively in neurons contributes to hyperinsulinemia and peripheral insulin resistance. However, it also suggests that, unlike in the case of general DHT exposure, i.c.v. DHT exposure does not lead to hyperglycemia.

$A R$ activation in female $\beta$ cells produces insulin hypersecretion in a cAMP-and mTOR-dependent manner. To explore the contribution of the AR in $\beta$ cells in vivo without the partial AR hypothalamic deletion observed in $\beta A R K O^{\mathrm{RIP}}$ mice, we generated a second $\beta$ cell-specific ARKO model ( $\beta$ ARKO ${ }^{\mathrm{MIP}}$ ) by crossing $\mathrm{AR}^{10 x}$ mice with MIP-Cre-transgenic mice (also known as Ins1-Cre/ERT mice) that lacks Cre activity in the hypothalamus (34). Unfortunately, the MIP-Cre-transgenic mouse has documented limitations due to transgene-driven expression of human growth hormone in islets, decreasing glucagon secretion, and improving peripheral insulin sensitivity (35). Therefore, the $\mathrm{AR}^{\mathrm{lox}} \mathrm{MIP}-\mathrm{Cre}$ mice must be used as controls of $\beta A R K O^{M I P}$ mice. Although this model proved reliable to demonstrate the importance of the AR in male $\beta$ cells (32), the model could not be used in females. Indeed, unlike in female AR $^{\text {lox }}$ or RIP-Cre controls used previously (Figures 2 and 4), DHT failed to induce fasting hyperinsulinemia and hyperglycemia, glucose-induced insulin hypersecretion, and insulin resistance in female $\mathrm{AR}^{\text {lox }}$ MIP-Cre mice (Supplemental Figure 5). Thus, the MIP-Cre transgene improves insulin sensitivity and blunts the effect of DHT. To circumvent this problem and to determine to what extent the DHT-induced hyperinsulinemia was islet cell autonomous, due to DHT action on AR in $\beta$ cells, we studied the effect of DHT on insulin secretion in static incubation of cultured islets from WD diet-fed female control and $\beta A R K \mathrm{O}^{\mathrm{RIP}}$ mice. Because of the deleterious effect of the RIP-Cre transgene on islet function (33), which is exacerbated by WD (32), we assessed insulin secretion selectively at high glucose concentrations (16.7 mM glucose). DHT exposure produced insulin hypersecretion in control islets, but this was not observed in $\beta A R K \mathrm{O}^{\mathrm{RIP}}$ islets (Figure $6 \mathrm{~A}$ ). We translated these findings to cultured islets from adult female human donors. Consistent with results obtained in the mouse, exposure of human islets to DHT produced insulin hypersecretion at high glucose levels compared with vehicle, and this effect was reversed in the presence of the AR antagonist flutamide (Figure 6C). Neither DHT, nor AR genetic elimination, nor pharmacological inhibition affected islet insulin content in mouse or human islets (Figure 6, B and D). To examine the effect of DHT on the responsiveness of isolated 


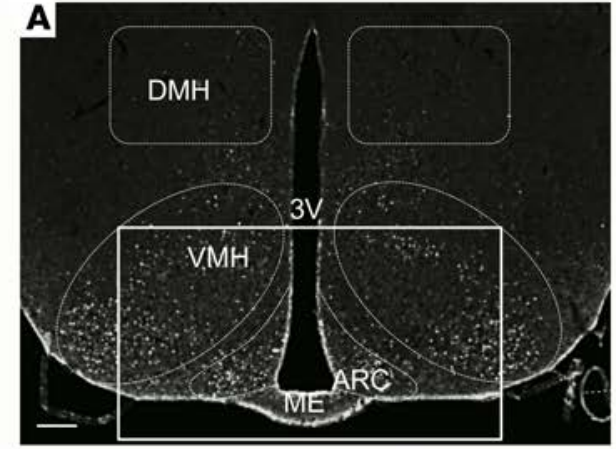

C

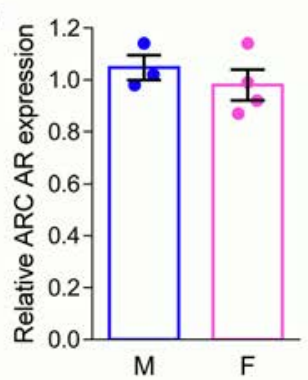

$\mathbf{F}$
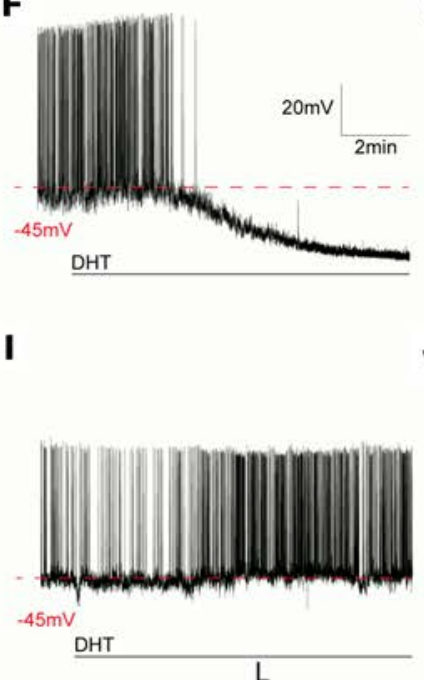

D

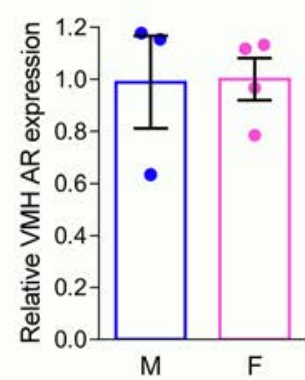

G

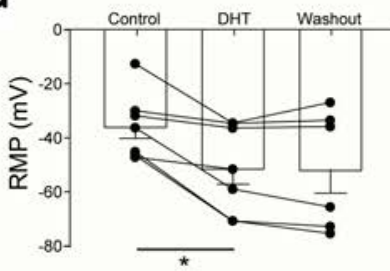

$\mathbf{J}$

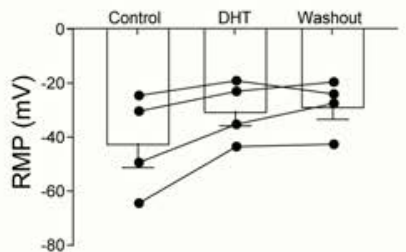

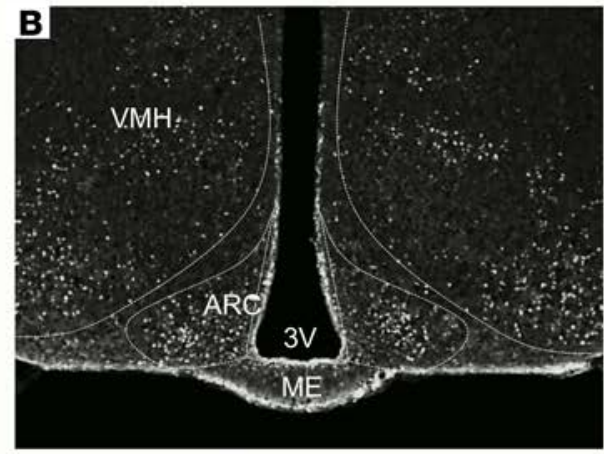

E

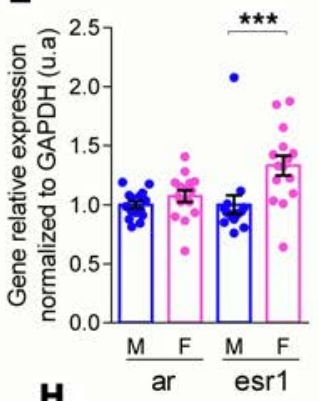

H

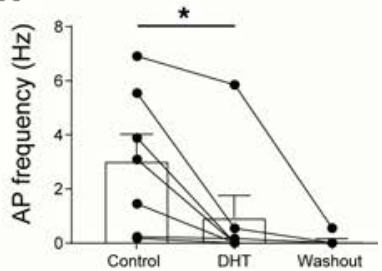

K

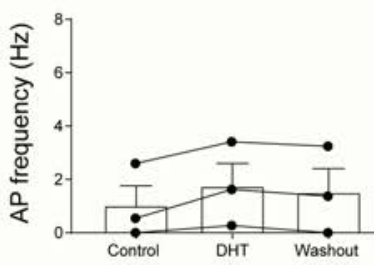

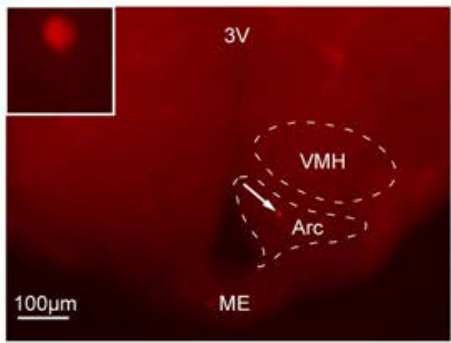

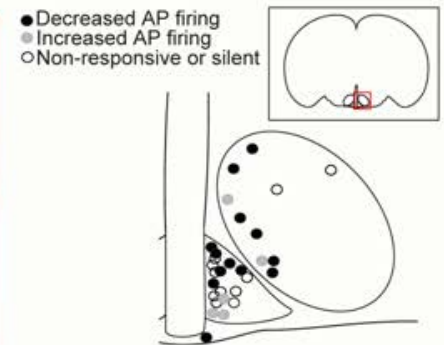

Figure 3. AR expression and activity in hypothalamic neurons of female mice. (A) AR staining in the MBH. Original magnification, $\times 40$ (scale bar: 100 $\mu \mathrm{m})$. (B) High-magnification image of the inset in A. (C) AR protein levels in the ARC and (D) the VMH. Data are expressed relative to the number of AR-positive cells in females $(n=3-4)$. (E) Estrogen receptor $\alpha$ (esr1) and AR relative mRNA expression in the MBH quantified by qPCR following microdissection. (F) Electrophysiological recordings of action potentials of a representative DHT-inhibited neuron or (I) a DHT-activated neuron in the ARC of wildtype females following treatment with DHT. (G and J) Resting membrane potential (RMP) and (H and $\mathbf{K}$ ) action potential frequency (AP) before and after application of DHT and following washout. (L) Biocytin staining of one representative recorded neuron in the ARC (scale bar: $100 \mu \mathrm{m})$ and an illustration of the localization of the recorded neurons. Values represent the mean \pm SEM with dot plots ( $n=15$ mice or $n=10-17$ neurons). ${ }^{*} P<0.05,{ }^{* * *} P<0.001$, Student's $t$ test, 1-way ANOVA or Friedman test. 
A

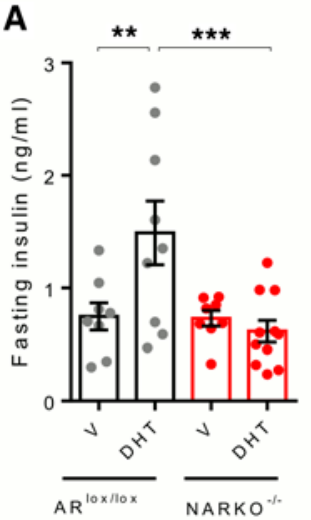

D

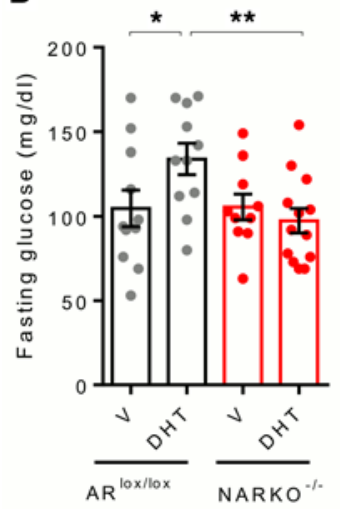

B

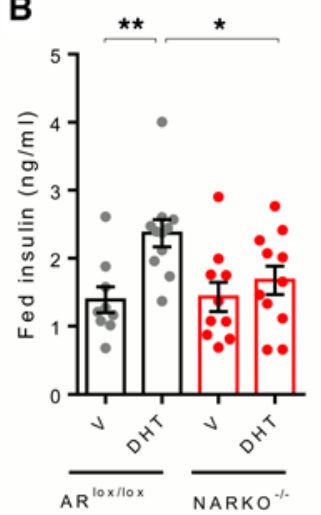

E

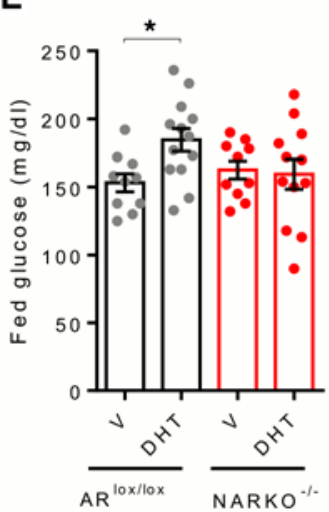

C
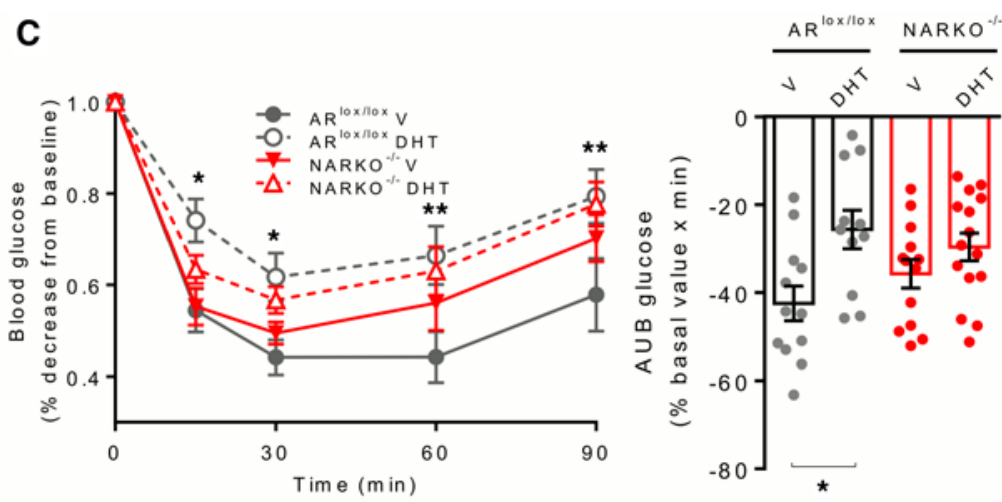

$\mathbf{F}$

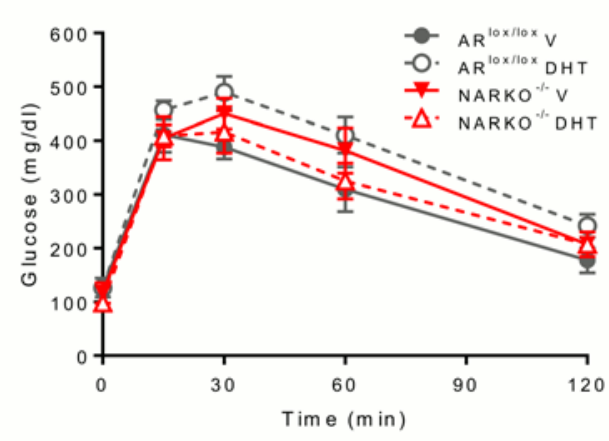

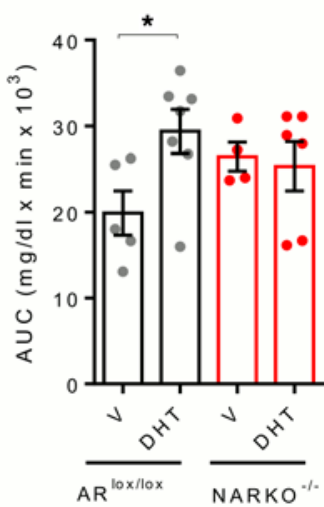

Figure 4. Chronic DHT excess predisposes female controls, but not NARKO-/- mice, to diabetes. AR ${ }^{\text {lox/lox }}$ or NARKO ${ }^{-/-}$mice were fed WD for 9 weeks followed by s.c. treatment with vehicle (V) or DHT for 4 weeks. (A) Fasting serum insulin levels. (B) Fed serum insulin levels. (C) Blood glucose represented as percentage decrease from baseline during an i.p. insulin tolerance test (ITT), with corresponding area under baseline (AUB). (D) Fasting blood glucose. (E) Random fed blood glucose. (F) Blood glucose during an i.p. glucose tolerance test (GTT) and corresponding AUC. Values represent the mean \pm SEM with dot plots $(n=4-15) .{ }^{*} P<0.05,{ }^{* *} P<0.01,{ }^{* *} P<0.001$, Student's $t$ test or 1-way or 2-way ANOVA.

islets with regard to first- and second-phase insulin secretion, we studied a batch of wild-type female mouse islets during a perifusion. Exposure to high glucose produced a classical rapid first-phase insulin release at 2 minutes followed by a second-phase starting at 5 minutes (36) (Figure 6E). Exposure to DHT produced an overall increased insulin secretion after both low and high glucose exposures (Figure 6E). Thus, in female islets, excess DHT produces insulin hypersecretion in response to glucose via AR activation in $\beta$ cells. GSIS is triggered by glucose metabolism, ultimately leading to the opening of $\mathrm{Ca}^{2+}$ channels and influx of intracellular calcium $\left[\mathrm{Ca}^{2+}\right]_{\mathrm{i}}(37)$. We explored whether DHT could increase $\left[\mathrm{Ca}^{2+}\right]_{\mathrm{i}}$ influx in female mouse islets. Raising glucose concentration increased $\left[\mathrm{Ca}^{2+}\right]_{\mathrm{i}}$ influx to a similar extent in both vehicle- and DHT-exposed islets (Figure 6F). The finding that DHT acting on AR enhanced GSIS without increasing cellular $\left[\mathrm{Ca}^{2+}\right]_{\mathrm{i}}$ influx suggests that AR activation amplifies GSIS by acting downstream of the $\mathrm{Ca}^{2+}$ signal, as it does in male islets, by increasing cAMP signaling (32). We studied DHT-induced cAMP production in female islets dynamically using the FRET probe Epac2 camps. Exendin 4 induced a rapid and sustained 2-fold increase in cAMP levels compared with vehicle controls. DHT exerted a similar stimulatory effect on cAMP levels, although the onset of the cAMP increase was slightly delayed compared with that after exendin 4 induction (Figure 6G). Since DHT activation of AR stimulates insulin secretion via cAMP production but independently from increase in $\beta$ cell mass, we reasoned that AR activation enhances GSIS via the protein kinase mTOR. Indeed, activation of $\mathrm{mTOR}$ in $\beta$ cells stimulates insulin secretion downstream of cAMP and without affecting $\beta$ cell mass (38). In addition, AR is known to activate mTOR in the prostate (39-41). In cultured islets from female mice fed a normal chow or a WD, inhibition of the TORC1 complex using rapamycin blocked the effect of DHT in enhancing GSIS after high glucose exposure (Figure 6H). However, the lack of specificity of rapamycin is a limitation of this agent. Therefore, we used a mouse overexpressing 1 copy of a kinase-dead mTOR mutant (KD-mTOR) transgene exclusively in $\beta$ cells. In cultured 
A
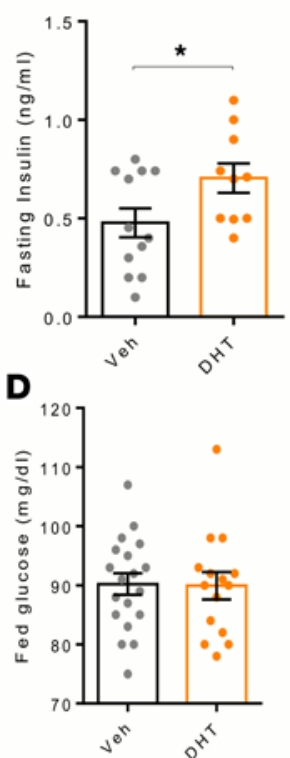

B

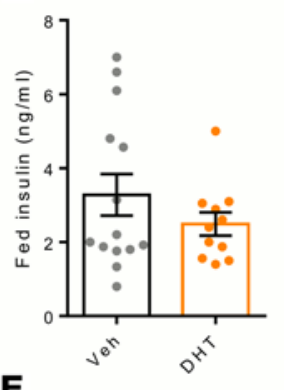

E

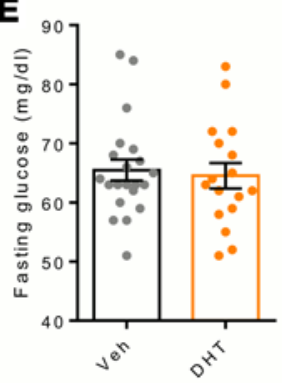

C
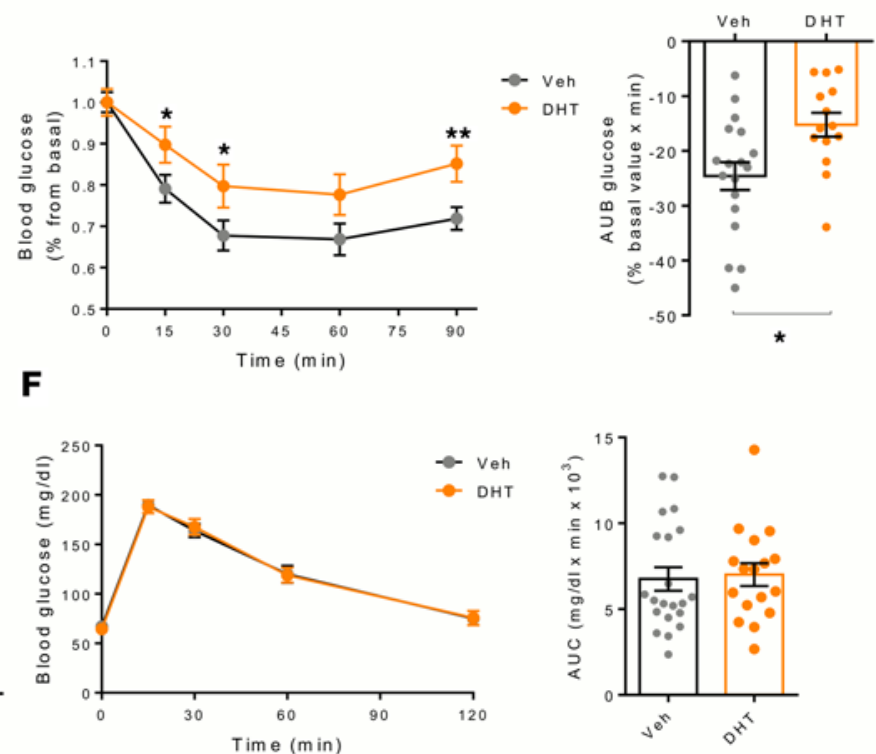

Figure 5. Chronic DHT perfusion in the brain produces insulin resistance in female mice. Female mice were fed WD for 9 weeks followed by i.c.v. infusion of vehicle (V) or DHT for 4 weeks. (A) Fasting serum insulin levels. (B) Fed serum insulin levels. (C) Blood glucose represented as an initial percentage decrease during an i.p. insulin tolerance test (ITT), with corresponding area under baseline (AUB). (D) Random fed blood glucose. (E) Fasting blood glucose. (F) Blood glucose during an i.p. glucose tolerance test (GTT) and corresponding AUC. Values represent the mean \pm SEM with dot plots $(n=10-21)$. ${ }^{*} P<$ $0.05,{ }^{* *} P<0.01$, Student's $t$ test or 2-way ANOVA.

islets from female KD-mTOR mice fed a normal chow, the effect of DHT in enhancing GSIS was abolished compared with that in WT islets (Figure 6I). Finally, in female mice fed a WD, the effect of chronic DHT exposure in promoting fasting and fed hyperinsulinemia and hyperglycemia, as described in Figures 2 and 4, was blunted following inhibition of the TORC1 complex with rapamycin treatment (Figure 6J). Thus, in female mice, excess DHT produces insulin hypersecretion in response to glucose via AR activation in $\beta$ cells in a cAMP- and mTOR-dependent manner.

Excess AR activation in $\beta$ cells produces mitochondrial hyperfunction and predisposes islets to oxidative injury. Since DHT excess produces insulin hypersecretion from female $\beta$ cells, we reasoned that chronic DHT exposure could enhance $\beta$ cell mitochondrial function. We studied mitochondrial oxygen consumption in female cultured islets exposed to DHT. Exposure of female islets to DHT increased the basal and total oxygen consumption rate (Figure 7A). Acute DHT exposure increases $\beta$ cell mitochondrial respiration and produces insulin hypersecretion in response to glucose, suggesting that chronic DHT exposure might cause $\beta$ cell exhaustion and injury. Consistent with this possibility, we previously reported that, following chronic exposure to testosterone, female mice were more susceptible to a second $\beta$ cell stress induced by streptozotocin (STZ) and were prone to insulin-deficient diabetes (42). Since STZ augments the generation of islet reactive oxygen species, resulting in islet oxidative stress $(43,44)$, we hypothesized that chronic AR activation in female $\beta$ cells promotes islet oxidative injury in vivo. To address this issue, we quantified lipid peroxidation (a marker of oxidative injury), using thiobarbituric acid reactive substances (TBARS) in female islets of WD-fed control and $\beta A R K \mathrm{O}^{\mathrm{RIP}}$ mice from experiments described in Figure 2. Chronic DHT exposure increased TBARS accumulation in control islets, consistent with the development of oxidative injury (Figure 7B). Although TBARS were increased at basal level in islets from $\beta A R K O^{R I P}$ mice compared with controls, DHT produced no further increase in TBARS accumulation in $\beta A R K O^{R I P}$ islets, consistent with a role for AR activation in $\beta$ cells in producing oxidative damage (Figure 7B). Having observed that chronic DHT exposure produces islet oxidative damage in female mice via AR in $\beta$ cells, we sought to determine to what extent chronic DHT action on the AR in $\beta$ cells exacerbates $\beta$ cell stress induced by the ROS inducer STZ in vivo. Following STZ challenge, as previously described $(45,46)$, female control mice were relatively protected. However, control mice exposed to DHT became more vulnerable to STZ and showed a greater predisposition to insulin-deficient diabetes with 


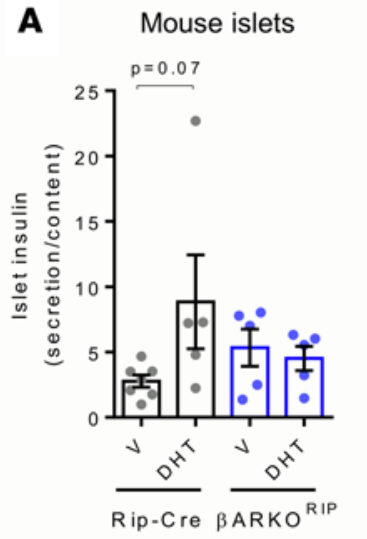

E

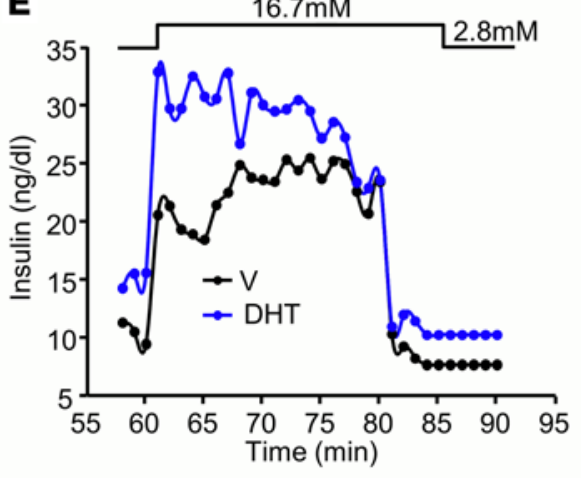

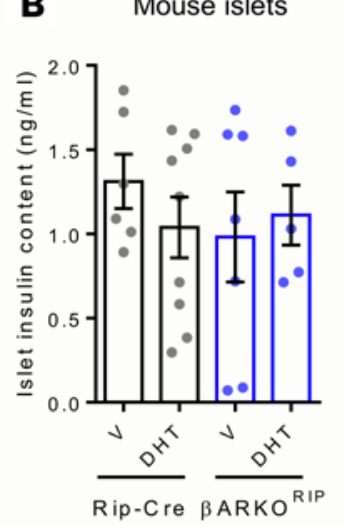

16.7mM

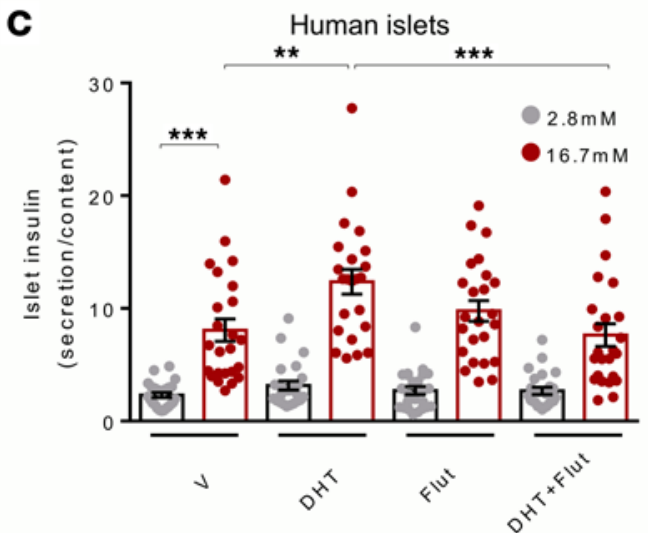

D Human islets
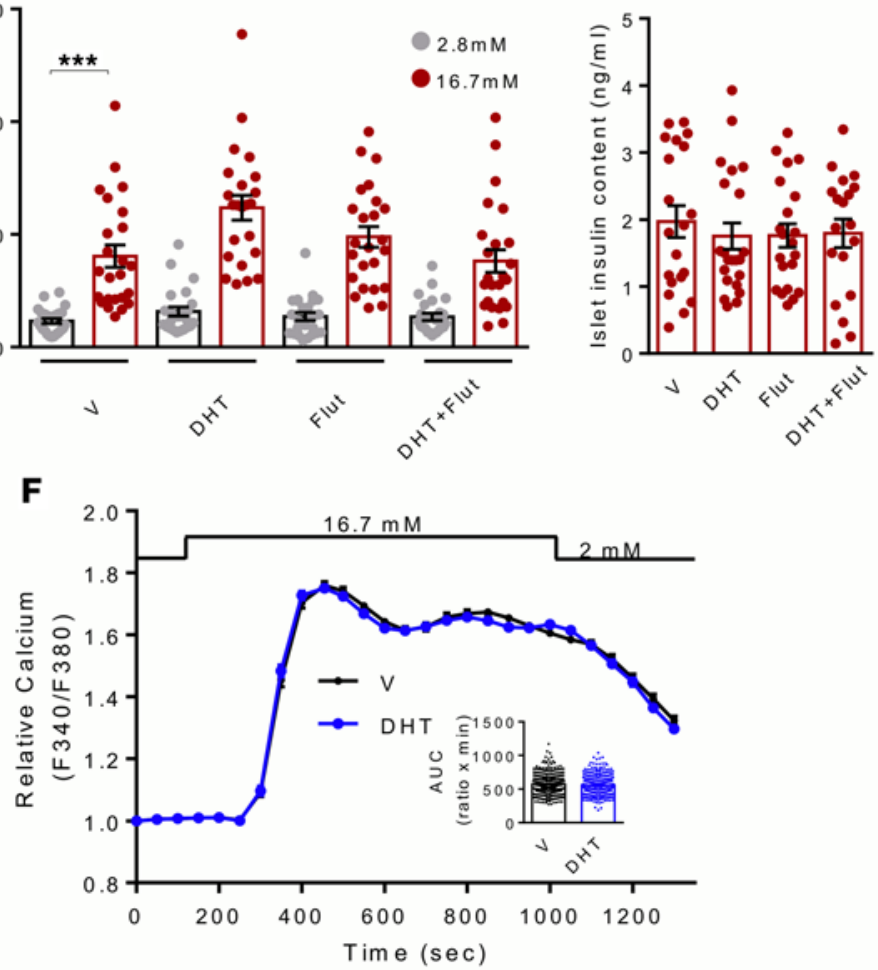
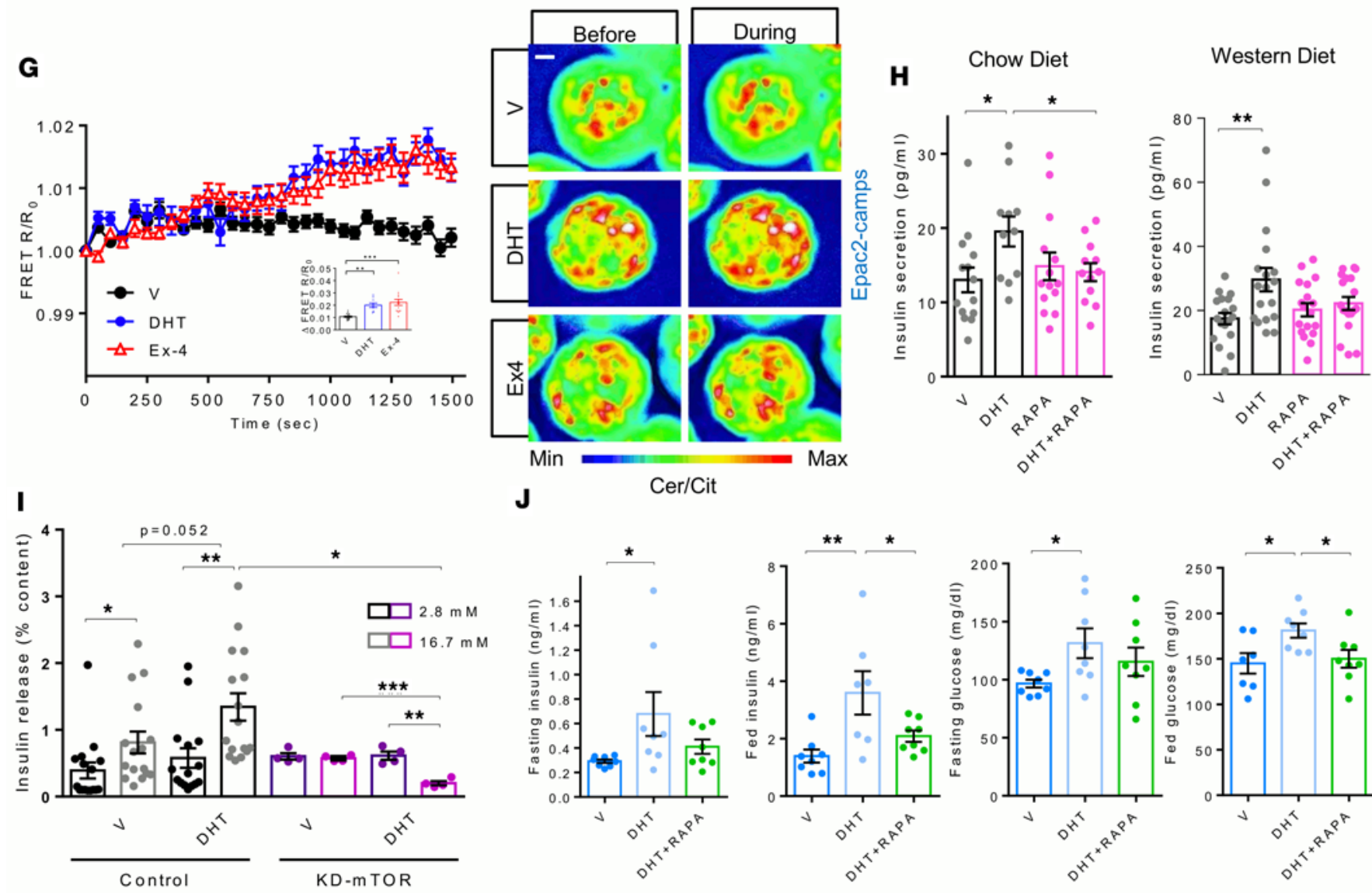

Western Diet

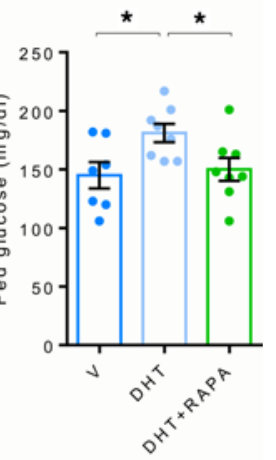


Figure 6. DHT enhances GSIS via an AR/cAMP/mTORC1 pathway. (A) GSIS measured in static incubation in islets from mice fed a WD for 8 weeks and treated with vehicle $(\mathrm{V})$ or $\mathrm{DHT}(10 \mathrm{nM})$ for 48 hours ex vivo. (B) Islet insulin content from A. Results represent 10 islets/condition in triplicate from $n \geq 3$ independent experiments. (C) Glucose-stimulated insulin secretion (GSIS) measured after static incubation in islets from female human donors. (D) Islet insulin content from C. Islets were treated V, DHT (10 nM), and or flutamide (Flut, $10 \mu \mathrm{M})$ in vitro for 48 hours. Results represent 5 islets per condition of $n=6$ independent experiments. (E) Basal and GSIS at the indicated glucose concentrations during a perifusion in WT female islets (vehicle, ethanol; DHT, $10 \mathrm{nM}$ ). Islets were isolated from mice at 14 weeks and perifused in batches of 60 per group. (F) Intracellular Ca $\mathrm{a}^{2+}$ influx and corresponding AUC from the indicated glucose concentrations in isolated female mouse islets ( $n=397$ cells for $\mathrm{V}, n=360$ cells for DHT). (C) $10 \mathrm{nM}$ DHT- and $10 \mathrm{nM}$ Ex-stimulated cAMP concentrations monitored in female mouse islets infected with adenovirus harboring the FRET probe Epac2 camps, with corresponding AUC and representative live cell imaging. Scale bar: $20 \mu \mathrm{m}$. (H) GSIS measured in static incubation in islets from WT female mice fed chow or WD, treated with V, DHT (10 nM), rapamycin (RAPA, $10 \mathrm{nM}$ ), or DHT+RAPA for 48 hours ( $n=12-14$ batches of 10 islets/condition, 4 independent experiments). (I) GSIS measured in static incubation in islets from female WT and KD-mTOR mice, treated as in A. Results represent 10 islets per condition of $n=4$ independent experiments. (J) WT female mice were exposed to WD for 4 weeks followed by 4 weeks of treatment with V, DHT, or DHT+RAPA ( $0.5 \mathrm{mg} / \mathrm{kg} / \mathrm{d} ; n=7-8 /$ group). Results represent the mean \pm SEM, with dot plots of fasting and fed serum insulin as well as fasting and fed blood glucose. ${ }^{* *} P<0.01,{ }^{* *} P<0.001,1$-way ANOVA.

exacerbated hyperglycemia (Figure 7, C and D) and hypoinsulinemia (Figure 7, E and F) as well as a more pronounced reduction in $\beta$ cell mass and pancreas insulin content (Figure $7, \mathrm{G}$ and $\mathrm{H}$ ). In contrast, in $\beta$ ARKO ${ }^{\mathrm{RIP}}$ mice, DHT produced no decrease in $\beta$ cell mass or pancreas insulin content and did not exacerbate STZ-induced insulin-deficient diabetes (Figure 7, C-H). Thus, in female mice, chronic DHT activation of $\mathrm{AR}$ in $\beta$ cells increases $\beta$ cell respiration and vulnerability to other oxidative or proapoptotic injuries and predisposes to $\beta$ cell failure.

\section{Discussion}

In this study, we have explored the hypothesis that androgen excess in female mice predisposes to T2D via chronic AR activation in the brain (producing peripheral insulin resistance) and in pancreatic islet $\beta$ cells (producing insulin hypersecretion and secondary $\beta$ cell failure). We have used a combination of mouse models in which (a) AR was activated globally (controls), (b) AR was activated globally except in $\beta$ cells and $\mathrm{MBH}$ hypothalamic neurons $\left(\beta \mathrm{ARKO} \mathrm{RIP}^{\mathrm{P}}\right)$, (c) AR was activated globally except in CNS neurons $\left(\mathrm{NARKO}^{-/-}\right)$, and (d) AR was activated selectively in the CNS. In addition, we used cultured islets from female mice and human donors. The combination of these models, when analyzed together, allows us to propose a paradigm in which excess and chronic AR activation in $\beta$ cells and neurons is instrumental in promoting hyperglycemia in hyperandrogenic female mice (summarized in Figure 8).

On a WD, female control mice exposed to androgen excess exhibit exaggerated insulin secretory response, hyperinsulinemia, and insulin resistance, but they fail to adequately compensate for insulin resistance and develop $\beta$ cell failure with hyperglycemia.

The first finding of this study is that excess AR activation in neurons is instrumental in the development of insulin resistance in these mice. The androgen-induced hyperinsulinemia and insulin resistance of female control mice was not observed in littermate $\mathrm{NARKO}^{-/-}$mice lacking AR selectively in neurons. Further, i.c.v. androgen infusion in wild-type female mice also produced fasting hyperinsulinemia and insulin resistance. Together, these results argue for the importance of neuronal ARs in androgen-induced insulin resistance. We reported that developmental or adult androgen excess in female mice alters the function of proopiomelanocortin (POMC) neurons in the ARC $(22,23)$. POMC neurons of the ARC are involved in peripheral insulin sensitivity. Leptin action in POMC neurons suppresses hepatic glucose production (18), and ablation of leptin and insulin receptors in POMC neurons produces insulin resistance and hyperandrogenism (19). Accordingly, enhancement of phosphoinositide 3-kinase signaling selectively in POMC neurons increases liver insulin sensitivity (20), and reexpression of leptin receptors exclusively in POMC neurons of leptin receptor-deficient mice normalizes blood glucose independently of obesity (21). Thus, excess AR activation in neurons of the $\mathrm{ARC}, \mathrm{VMH}$, or in other areas that influence $\mathrm{MBH}$ neurons may alter insulin or leptin action in POMC neurons and produce peripheral insulin resistance. This does not exclude the possibility that androgen excess can produce insulin resistance via AR activation in peripheral tissues. In fact, excess AR activation in hepatocytes of adult female mice causes hepatic insulin resistance (47). Studies are needed to identify the exact AR-expressing hypothalamic neurons that are targeted by androgens to promote peripheral insulin resistance.

Unlike others (47), we did not observe androgen-induced insulin resistance with normal rodent chow. The most likely explanation for this discrepancy is the impact of different vivarium environments. Indeed, differences in exogenous sources of soy phytoestrogens coming from normal rodent chow and the influence of different metagenomes (the interaction between host and microbiome genes) influence the experimental reproducibility of in vivo studies on glucose metabolism (48). 

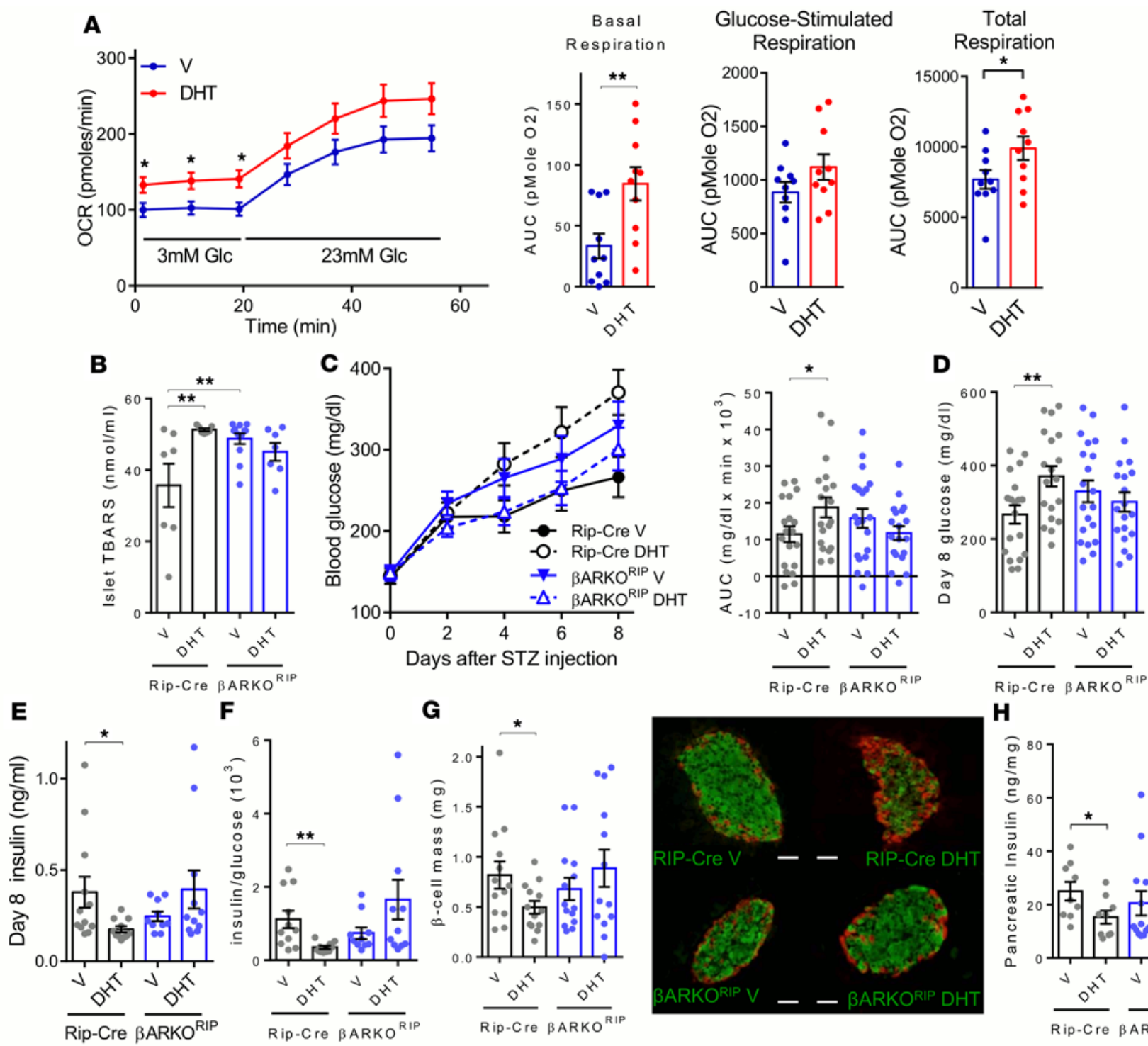

$\mathbf{F}$

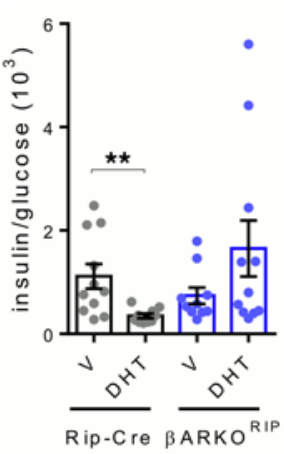

G

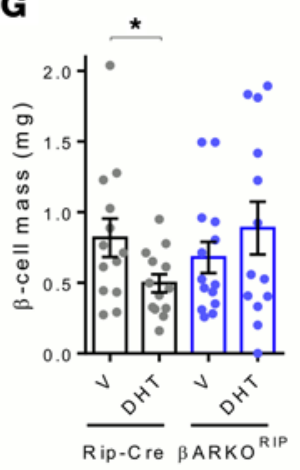

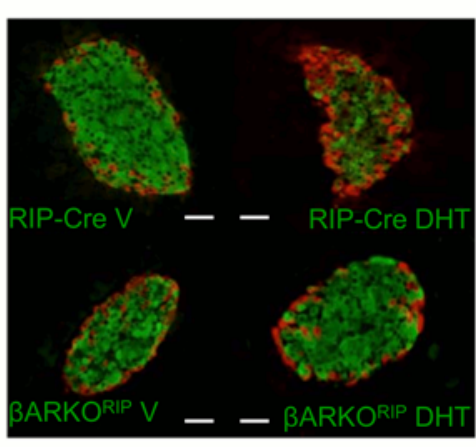

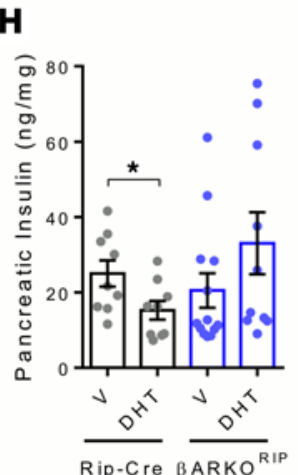

Figure 7. Chronic AR activation in $\beta$ cells predisposes to oxidative stress. (A) Oxygen consumption rate (OCR) measured from islets isolated from 10 female mice treated with vehicle $(\mathrm{V})$ or DHT $(10 \mathrm{nM})(n=10$ wells/condition). (B) Islet TBARS from 13-week-old mice from Figure 2 ( $n=7-12)$. (C-H) Mice were treated s.c. with $\mathrm{V}$ or DHT for 1 week followed by induction of diabetes with a single high dose of streptozotocin (STZ) ( $n=9-20)$. (C) Blood glucose measured for 8 days following STZ-induced diabetes and corresponding AUC. (D) Random-fed blood glucose (day 8). (E) Random fed insulin levels (day 8). (F) Insulin/glucose ratio. (C) $\beta$ Cell mass quantification and IHC images of representative islets. Scale bar: $10 \mu \mathrm{m}$. (H) Pancreatic insulin concentration. Values represent the mean \pm SEM with dot plots. ${ }^{*} P<0.05,{ }^{* *} P<0.01$, 1-way ANOVA.

The second finding of this study is that during WD feeding, excess AR activation in $\beta$ cells is necessary for the development of hyperglycemia. Several lines of evidence support this possibility. First, acute androgen exposure produces insulin hypersecretion in an AR-dependent manner in cultured female mouse and human islets, with an exaggerated first- and second-phase of insulin secretion during perifusion. Second, chronic androgen excess in vivo produces islet oxidative injury via AR in $\beta$ cells. Finally, and importantly, in wild-type female mice, peripheral androgen infusion (which targets neurons and $\beta$ cells) produces hyperinsulinemia, insulin resistance, and hyperglycemia, consistent with $\beta$ cell failure. In contrast, i.c.v. androgen infusion (which selectively targets central neurons but not $\beta$ cells) produces fasting hyperinsulinemia and insulin resistance without hyperglycemia, consistent with retained $\beta$ cell function. Thus, during WD feeding, excess AR activation in $\beta$ cells and neurons causes insulin resistance and hyperglycemia, but excess AR activation selectively in neurons produces insulin resistance without hyperglycemia. This argues for a role of chronic $\beta$ cell AR activation in the development of hyperglycemia, independent of insulin resistance. How does 


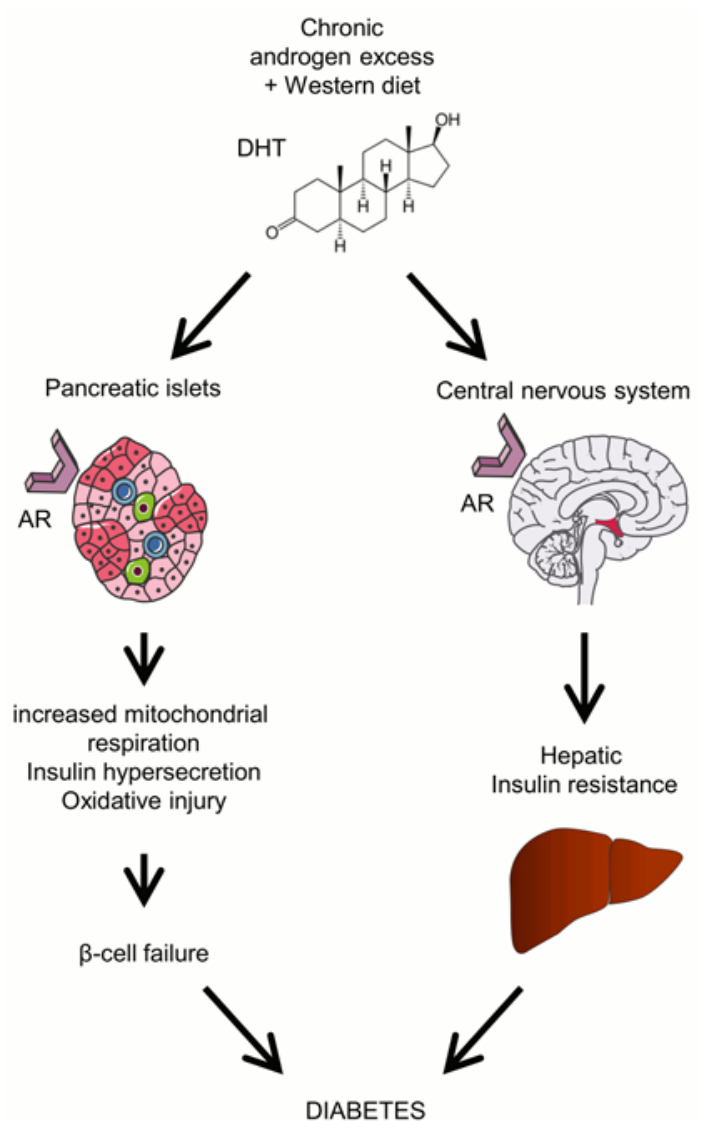

Figure 8. Proposed mechanism for the development of diabetes in female mice with chronic androgen excess. In female mice exposed to a Western diet, chronic androgen excess predisposes to T2D through the combined activation of AR in the hypothalamus, producing hepatic insulin resistance, and activation of AR in $\beta$ cells, increasing oxygen consumption and producing insulin hypersecretion, oxidative injury, and secondary failure.

excess AR activation in $\beta$ cells predispose them to failure? Testosterone increases mitochondrial respiration and accordingly promotes islet oxidative damage in vivo. Female mice exposed to testosterone become more susceptible to additional islet oxidative stress induced by either a WD or STZ, which is not observed in $\beta A R K O^{\text {RIP }}$ mice, arguing for the importance of the $\beta$ cell AR in $\beta$ cell injury. This suggests that, in the presence of a prior islet metabolic stress, the deleterious effect of chronic AR activation causes $\beta$ cell hyperfunction, mitochondrial activation, and oxidative stress, which predisposes to $\beta$ cell demise in female mice.

Interestingly, there is a bidirectional modulation of metabolic homeostasis by testosterone in males and females. In males, physiological concentrations of testosterone are necessary to

maintain insulin sensitivity and $\beta$ cell function, and testosterone deficiency predisposes to diabetes (24, $25,32)$. In contrast, in females, increasing circulating testosterone concentrations to levels observed in males produces insulin resistance and $\beta$ cell dysfunction and predisposes to diabetes. This sex dimorphism underscores the fundamental differences between male and female biological systems that are rooted in genetics, development, and puberty (48).

There are important clinical ramifications to this study. Women with PCOS exhibit insulin resistance, with testosterone levels positively correlated to the degree of insulin resistance (49). In addition, these women exhibit exaggerated insulin secretion unrelated to insulin resistance and closely associated with androgen excess, suggesting that testosterone produces insulin hypersecretion and $\beta$ cell dysfunction (2831). Thus, the predisposition to T2D in women with PCOS and androgen excess could result, as in the case of our mouse model, from the effect of testosterone on brain and $\beta$ cells.

In summary, chronic androgen excess in female mice fed a WD predisposes to T2D. These effects require the combined effect of a metabolic stress and AR activation in the hypothalamus (producing insulin resistance) and in $\beta$ cells (producing insulin hypersecretion and injury), which together contribute to secondary $\beta$ cell failure and hyperglycemia (Figure 8)

\section{Methods}

Experimental animals. The $\beta A R K \mathrm{R}^{\mathrm{RIP}}$ and neuronal specific knockout ( $\left.\mathrm{NARKO}^{-/-}\right)$mice were generated by crossing $\mathrm{AR}^{\mathrm{lox} /+}$ mice with RIP-Cre ${ }^{+/-}$and Syn-Cre ${ }^{+/-}$transgenic mice (Jackson Laboratory), respectively, as described previously (32). $\mathrm{AR}^{\text {lox/lox }} \mathrm{MIP}-\mathrm{CreERT}$ mice were generated by crossing $\mathrm{AR}^{\text {lox/lox }}$ mice with MIP-CreERT1 ${ }^{\text {Lphi }}$ (MIP-CreERT) transgenic mice (Jackson Laboratory). The inducible $\beta A R K O^{\text {MIP-ERT }}$ mice were produced by treating $\mathrm{AR}^{\text {lox/lox }}$ MIP-CreERT mice with Tam after puberty as described previously (15). $\beta \mathrm{ARKO}^{\mathrm{MIP}}$ mice were generated by crossing $\mathrm{AR}^{\text {lox/+ }}$ mice with Ins $1^{\text {tm1.1(cre)Thor } / ~}$ $\mathrm{J}-C r e^{+/-}$transgenic (MIP-Cre-transgenic) mice (Jackson Laboratory). Androgen excess was induced via implantation of a $20 \mathrm{~mm}$ DHT pellet prepared as described previously (47). KD-mTOR mice were generated as described previously (38). All transgenic mice described above were on a C57BL/6 mouse 
background. Brain infusion studies were performed using female C57BL/6 mice from Charles River, while electrophysiological studies and gene expression studies used C57BL/6J mice from Jackson Laboratories. All studies were performed on littermate mice aged 10-16 weeks.

WD and in vivo induction of androgen excess. Mice were weaned on a WD high in saturated fat and simple sugars (sucrose and fructose) (30\% AMF diet; 14.9\% Kcal protein, 33.2\% Kcal carbohydrates, 51.9\% Kcal fat; Harlan Teklab). DHT and vehicle were administered to mice after 4 weeks of WD by s.c. pellets (10 mg/pellet, 60-day release; Innovative Research of America) or via i.c.v. injection for an additional 4-5 weeks. To infuse DHT i.c.v., a cannula was implanted into the lateral ventricle (coordinates compared with the bregma $\mathrm{L}+1 \mathrm{~mm}, \mathrm{AP}-0.2 \mathrm{~mm}, \mathrm{DV}-2 \mathrm{~mm}$ ) using a stereotaxic frame (Kopf), linked to a DHT-filled osmotic minipump (Alzet) inserted subcutaneously.

Metabolic studies. Metabolic studies were performed 1 week apart following 4 weeks of s.c. or i.c.v. DHT exposure. Blood glucose and insulin concentrations were measured from blood drawn from tail veins using a TRUEResults glucose meter (NitroDiagnostics) and insulin ELISA kit (Linco Research and Millipore), respectively. For i.p. glucose tolerance test $(2 \mathrm{~g} / \mathrm{kg})$ or i.p. GSIS $(3 \mathrm{~g} / \mathrm{kg})$, mice were fasted overnight before glucose injection. For i.p. ITT (0.25-0.5 U/kg), mice were fasted for 6 hours and given insulin. Blood glucose and plasma insulin were assessed at the indicated times as described. Pancreas insulin concentration was quantified by acid ethanol extraction as described previously (32).

Inhibition of mTORC-1 in vivo. Mice were weaned on a WD as described above. After 4 weeks of WD, mice were exposed to vehicle, DHT, and DHT plus rapamycin (Santa Cruz Biotechnology) for an additional 4 weeks. Rapamycin was injected i.p. at $5 \mathrm{mg} / \mathrm{kg}$ every day.

Induction of experimental diabetes. One week following DHT pellet insertion, 9-week-old mice were exposed to a single i.p. injection of $150 \mathrm{mg} / \mathrm{kg} \mathrm{STZ} \mathrm{(MilliporeSigma)} \mathrm{to} \mathrm{induce} \mathrm{diabetes} \mathrm{as} \mathrm{described} \mathrm{previously} \mathrm{(42).} \mathrm{Blood}$ glucose was measured every 48 hours following STZ injection. At day 8 following STZ injection, insulin was assessed and pancreases were processed for measurement of pancreatic insulin concentration and $\beta$ cell mass.

Immunohistochemistry and $\beta$ cell mass quantification. Pancreases were fixed, paraffin embedded, and sectioned at $5 \mu \mathrm{m}$. Brains were fixed via transcardial perfusion of $10 \%$ formalin and sectioned at $20 \mu \mathrm{m}$. Antigen retrieval and section incubation with primary and secondary antibodies were performed as described previously (32). Images were captured at $\times 20$ magnification using a fluorescent microscope (Nikon Eclipse E400 or TissueGnostics Imaging). The $\beta$ cell mass was quantified by morphometric analysis as described previously (32). All islets were imaged from 1 section per animal $(n=3-4)$ per group.

Islet isolation and insulin secretion in static incubation. Female mouse islets were isolated following pancreatic duct catheterization, collagenase digestion, and Histopaque gradient separation as described previously (32). Following overnight recovery, islets were hand-picked under a dissection microscope, transferred to a 24 -well plate (10 islets/well), and cultured in phenol red-free RPMI (11 mM glucose, 10\% charcoal-stripped FBS). Islets from female human donors (provided by the Integrated Islet Distribution Program) were cultured in phenol red-free CMRL 1066 with 10\% charcoal-stripped FBS. Islets were treated with DHT (10-8 M; Steraloids), Flutamide (10 $\mu \mathrm{M}$; MilliporeSigma), or vehicle (95\% ethanol) for 48 hours. Insulin release from islets was measured by static incubation using 10 islets/well as described previously (32). Insulin was measured by ELISA (Millipore).

Islet perifusion. Batches of 60 mouse islets (C57BL/ 6 females) were perifused at $37^{\circ} \mathrm{C}$, at a flow of $100 \mu 1 / \mathrm{min}$, as described previously (32). Islets were first equilibrated for 60 minutes with Krebs-Ringer buffer (KRB) solution containing $2.8 \mathrm{mM}$ glucose and then stimulated for 30 minutes with KRB solution containing either DHT $\left(10^{-8} \mathrm{M}\right)$ or vehicle $(95 \%$ ethanol) and $16.7 \mathrm{mM}$ glucose. Samples were collected in a 96-well plate. A perifusion system (Biorep Technologies) was used to determine biphasic response and insulin concentration was determined by ELISA.

Cytoplasmic calcium imaging. Whole islet intracellular $\mathrm{Ca}^{2+}$ influx was measured as described previously (32). Briefly, islets were plated on glass-bottom MatTek plates in RPMI media without phenol red and 10\% charcoal-stripped FBS (Invitrogen) with either DHT $\left(10^{-8} \mathrm{M}\right)$ or vehicle (95\% ethanol). Islets were cultured in a TC incubator $\left(37^{\circ} \mathrm{C}, 5 \% \mathrm{CO}_{2}\right)$ for 48 hours, during which time the media were replaced every 12 hours. Islets were then loaded with fura- $2(2 \mu \mathrm{mol})$ for 20 minutes in modified KRB containing $2 \mathrm{mM} / 1$ glucose, $119 \mathrm{mM} / 1 \mathrm{NaCl}, 2.5 \mathrm{mM} / 1 \mathrm{CaCl} \cdot[(\mathrm{H} 2 \mathrm{O}) 6], 4.7 \mathrm{mM} / 1 \mathrm{KCl}, 10 \mathrm{mM} / 1 \mathrm{HEPES}, 1.2 \mathrm{mM} / \mathrm{MgSO}_{4}, 1.2$ $\mathrm{mM} / 1 \mathrm{KH}_{2} \mathrm{PO}_{4}, \mathrm{pH}$ 7.3. $\mathrm{Ca}^{2+}$ imaging was performed using a Nikon microscope (TE2000-U) with illumination from a 300-watt xenon arc lamp (Lamba LS, Sutter instruments) and imaging with a cooled CCD camera (CoolSNAP HQ2 camera, Photometrics). Islets were perifused $(2 \mathrm{ml} / \mathrm{min})$ with $\mathrm{KRB}$ media at 
$37^{\circ} \mathrm{C}$ containing either 2 or $16.7 \mathrm{mM}$ glucose and DHT or vehicle. The relative $\left[\mathrm{Ca}^{2+}\right]_{\mathrm{i}}$ was determined from the ratio of emitted fura-2 fluorescence with $340 \mathrm{~nm}$ or $380 \mathrm{~nm}$ excitation (F340/F380).

Dynamic measurement of islet cAMP. Islets were isolated from 8-week-old female Ins1-Cre ${ }^{+/-}$knockin mice on a C57BL6/J background. These animals have previously been shown to be indistinguishable from Ins1-Cre $\mathrm{C}^{-/-}$littermates in terms of growth, glucose tolerance, insulin tolerance, in vivo and in vitro insulin release, and $\beta$ cell mass $(50,51)$. The levels of cAMP were monitored in islets infected with adenovirus harboring the FRET probe Epac2 camps, as previously described (52). Live-cell imaging was performed using a Crest X-Light spinning disk head, coupled to a Lumencor SPECTRA $\mathrm{X}$ light engine and Nikon $10 \times / 0.45$ NA objective, controlled using custom scripts in MetaMorph software (Molecular Devices). Excitation was delivered at $\lambda=430-450 \mathrm{~nm}$ and emission was collected at $\lambda=460-500 \mathrm{~nm}$ and 520-550 $\mathrm{nm}$ for cerulean (Cer) and citrine (Cit), respectively, using a highly sensitive Photometrics Delta Evolve EMCCD camera. FRET response was calculated as the fluorescence ratio of Cer/Cit and normalized as $R / R_{0}$, where $R$ denotes fluorescence at any given time point and $R_{0}$ denotes fluorescence at time 0 . Islets were maintained in HEPES-bicarbonate buffer, containing 120 $\mathrm{mM} \mathrm{NaCl}, 4.8 \mathrm{mM} \mathrm{KCl}_{2} 24 \mathrm{mM} \mathrm{NaHCO}_{3}, 0.5 \mathrm{mM} \mathrm{Na}_{2} \mathrm{HPO}_{4}, 5 \mathrm{mM} \mathrm{HEPES} 2.5 \mathrm{mM} \mathrm{CaCl}, 1.2 \mathrm{mM}$ $\mathrm{MgCl}_{2}, 3-17 \mathrm{mM}$ D-glucose and $\mathrm{Ca}^{2+}$. Vehicle $(0.01 \% \mathrm{EtOH})$, DHT (10 nM), and exendin $4(10 \mathrm{nM})$ were applied at the indicated time points.

$T B A R S$ assay. Islet oxidative stress was assessed in islets isolated from mice fed a WD and treated with DHT in vivo by measuring the concentration of TBARS (Zeptometrix) as described previously (42).

Seahorse assay. Islets isolated from 10 female C57/BL6N mice were washed once with assay buffer (made from Agilent Seahorse XF Base Medium supplemented with $3 \mathrm{mM}$ glucose and 1\% charcoal-striped FBS). Around 70 islets were transferred to each well of a Seahorse XF24 Islet Capture Microplate (Agilent) and were incubated in assay buffer at $37^{\circ} \mathrm{C}$ for 60 minutes before being transferred to Seahorse XF Analyzer (Agilent). Islets were maintained in the assay medium throughout the experiment, and the oxygen consumption rate was measured at the basal level $(3 \mathrm{mM})$ as well as at a glucose-stimulated level $(20 \mathrm{mM})$. The results were normalized to the results of the first time point of the vehicle-treated group.

Microdissection of $\mathrm{MBH}$. Male and female $(n=15)$ mice were sacrificed with $\mathrm{CO}_{2}$ and decapitated, and brains were dissected into 1-mm coronal sections with the help of an ice-cold mouse brain matrix (ASI-Instruments). From the brain slice covering approximately Bregma $-1.0 \mathrm{~mm}$ to $-2.0 \mathrm{~mm}$, the hypothalamus was detached by a horizontal cut through the mammillothalamic tracts. The lateral hypothalamus was removed by a bilateral cut through the fornix, and the remaining hypothalamic piece was horizontally divided with a cut across the fornix to generate a ventral portion with VMH/ ARC enrichment and a dorsal portion with $\mathrm{DMH}$ enrichment. The dissected brain tissue was snap frozen and stored at $-80^{\circ} \mathrm{C}$ until RNA extraction.

$R N A$ extraction, cDNA synthesis, and $q P C R$. RNA from ARC/VMH tissue was extracted by first homogenizing each sample in Trizol (Life Technologies) with a hand-held homogenizer (PELLET PESTLE Cordless Motor, Kimble Chase) and sterile pellet pestles (Kimble Chase), according to the manufacturer's recommendations. To minimize DNA and protein contamination, $100 \mu 1$ phase separation reagent was added (1-bromo-3-chloropropane, Molecular Research Center Inc.) during the extraction protocol. cDNA was synthesized by reverse transcription PCR (SuperScript VILO, Invitrogen) according to the manufacturer's recommendations.

For quantitative PCR, $3 \mu \mathrm{l}(1.4 \mathrm{ng} / \mu \mathrm{l})$ template cDNA was used in triplicate to determine gene expression with TaqMan assays (TaqMan Universal Master Mix II, with UNG, Applied Biosystems by Thermo Fisher Scientific) for Gapdh (Mm99999915_g1), Ar (Mm00442688_m1), and Esr1 (Mm00433149_m1), with Gapdh serving as a housekeeping gene. Reactions were pipetted by a robotic liquid handling system (Perkin Elmer Multiprobe II EX) and run on the 7500 HT Fast Real-Time PCR System (Applied Biosystems). Fold induction of gene expression was analyzed with the $\Delta \Delta \mathrm{CT}$ method, as recommended for TaqMan assays.

Whole-cell patch-clamp recordings and identification of recorded neurons. Whole-cell patch-clamp recordings were performed at $34^{\circ} \mathrm{C}-37^{\circ} \mathrm{C}$ from neurons of the VMH or the ARC of 10 -week-old female C57BL6J mice as previously described (53). DHT (10 nM) was used to determine the effects of AR activation on neuronal activity. After recordings, slices were fixed in paraformaldehyde $(4 \%)$ and stored at $4^{\circ} \mathrm{C}$. Following a rinse in PBS, slices were incubated in a PBS (10 mM), Texas red Avidin D (1:400) and Triton X-100 (1\%) solution at room temperature for 4 hours, mounted, and coverslipped with Vectashield (Vector Laboratories).

Statistics. Results are presented as dot plots and mean \pm SEM, as specified in figures. Statistical analyses 
were performed using the unpaired 2-tailed Student's $t$ test, 1-way ANOVA or Mann-Whitney tests, and Kruskal-Wallis test, when necessary. Cumulative incidence of diabetes was determined by Kaplan-Meier estimates, and statistical analysis of differences was determined by a log-rank test. A $P$ value of less than 0.05 was considered statistically significant.

Study approval. Studies were performed with the approval of the Northwestern University, Tulane University (New Orleans, Louisiana, USA), Pennington Biomedical Research Center, and University of Miami Animal Care and Use Committees and in accordance with NIH guidelines.

\section{Author contributions}

GN designed and conducted the experiments (Figure 1; Figure 2; Figure 4; Figure 6, A-E, H, and J; Figure 7, B-H; and Supplemental Figures 1-3), analyzed the data, and wrote/reviewed the manuscript. CA (Figure 5 and Supplemental Figures 4 and 5), JJM (Figure 3, A-D; Figure 5; and Supplemental Figures 4 and 5), and WX (Figure 7A) designed experiments, analyzed data, contributed to discussion, and reviewed the manuscript. SL (Figure 7, B-H), AJRM and SMB (Figure 3, F-L), SY and RZ (Figure 3E), NHFF (Figure 6G), and MBR (Figure 6I) conducted experiments and analyzed data. DAJ conducted intracellular $\mathrm{Ca}^{2+}$ influx experiments (Figure 6F). VNS and PVK designed experiments, analyzed data, contributed to discussion, and reviewed the manuscript (Figure 7A). DJH, HM, EBM, and AZ designed experiments, contributed to discussion, and reviewed the manuscript. FMJ conceived the idea, designed experiments, analyzed the data, and wrote and reviewed the manuscript. FMJ is the guarantor of this work and, as such, had full access to all the data in the study and takes responsibility for the integrity of the data and the accuracy of the data analysis.

\section{Acknowledgments}

This work was supported by grants from the NIH (R01 DK074970, DK107444, and P50 HD044405) and a Department of Veterans Affairs Merit Review Award (BX003725) to FMJ. CA was supported by an American Diabetes Association Postdoctoral Fellowship (1-16-PDF-004). AZ was supported by NIH grant R01 DK099598, EBM was supported by NIH grants R01 DK073716 and DK084236 and a Veterans Affairs Merit Review Award (IBX002728A), HM was supported by NIH grant R01 DK092587, and PVK was supported by NIH grant R01 NS094834. DJH was supported by a Diabetes UK RD Lawrence Fellowship (12/0004431), a Wellcome Trust Institutional Support Award, and MRC (MR/N00275X/1) and Diabetes UK (17/0005681) project grants as well as by the European Research Council under the European Union's Horizon 2020 research and innovation programme (starting grant 715884). Part of this work was presented during the American Diabetes Association meeting in New Orleans, Louisiana, USA, on June 10-14, 2016.

Address correspondence to: Franck Mauvais-Jarvis, Section of Endocrinology and Metabolism, Tulane University Health Sciences Center, New Orleans, Louisiana 70112, USA. Phone: 504.988.5990; Email: fmauvais@tulane.edu.

1. Achard C, Thiers J. Le virilisme pilaire et son association a l'insuffisance glycolytique (diabete des femmes a barbe). Bull Acad Natl Med Paris. 1921;86:51-55.

2. Ding EL, Song Y, Malik VS, Liu S. Sex differences of endogenous sex hormones and risk of type 2 diabetes: a systematic review and meta-analysis. JAMA. 2006;295(11):1288-1299.

3. Rubin KH, Glintborg D, Nybo M, Abrahamsen B, Andersen M. Development and risk factors of type 2 diabetes in a nationwide population of women with polycystic ovary syndrome. J Clin Endocrinol Metab. 2017;102(10):3848-3857.

4. Legro RS, Kunselman AR, Dodson WC, Dunaif A. Prevalence and predictors of risk for type 2 diabetes mellitus and impaired glucose tolerance in polycystic ovary syndrome: a prospective, controlled study in 254 affected women. J Clin Endocrinol Metab. 1999;84(1):165-169.

5. Ehrmann DA, Barnes RB, Rosenfield RL, Cavaghan MK, Imperial J. Prevalence of impaired glucose tolerance and diabetes in women with polycystic ovary syndrome. Diabetes Care. 1999;22(1):141-146.

6. Spiegelman BM, Flier JS. Adipogenesis and obesity: rounding out the big picture. Cell. 1996;87(3):377-389.

7. Naftolin F, Ryan KJ, Davies IJ, Petro Z, Kuhn M. The formation and metabolism of estrogens in brain tissues. Adv Biosci. 1975;15:105-121.

8. Moghetti $\mathrm{P}$, et al. The insulin resistance in women with hyperandrogenism is partially reversed by antiandrogen treatment: evidence that androgens impair insulin action in women. J Clin Endocrinol Metab. 1996;81(3):952-960.

9. Negri-Cesi P, Colciago A, Pravettoni A, Casati L, Conti L, Celotti F. Sexual differentiation of the rodent hypothalamus: hormonal and environmental influences. J Steroid Biochem Mol Biol. 2008;109(3-5):294-299.

10. Zisman A, et al. Targeted disruption of the glucose transporter 4 selectively in muscle causes insulin resistance and glucose intolerance. Nat Med. 2000;6(8):924-928. 
11. Brüning JC, et al. A muscle-specific insulin receptor knockout exhibits features of the metabolic syndrome of NIDDM without altering glucose tolerance. Mol Cell. 1998;2(5):559-569.

12. Brüning JC, et al. Role of brain insulin receptor in control of body weight and reproduction. Science. 2000;289(5487):2122-2125.

13. Mauvais-Jarvis F, Kahn CR. Understanding the pathogenesis and treatment of insulin resistance and type 2 diabetes mellitus: what can we learn from transgenic and knockout mice? Diabetes Metab. 2000;26(6):433-448.

14. Kulkarni RN, Brüning JC, Winnay JN, Postic C, Magnuson MA, Kahn CR. Tissue-specific knockout of the insulin receptor in pancreatic beta cells creates an insulin secretory defect similar to that in type 2 diabetes. Cell. 1999;96(3):329-339.

15. Yu IC, et al. Neuronal androgen receptor regulates insulin sensitivity via suppression of hypothalamic NF- $\mathrm{B}$-mediated PTP1B expression. Diabetes. 2013;62(2):411-423.

16. Brown RE, Wilkinson DA, Imran SA, Caraty A, Wilkinson M. Hypothalamic kiss 1 mRNA and kisspeptin immunoreactivity are reduced in a rat model of polycystic ovary syndrome (PCOS). Brain Res. 2012;1467:1-9.

17. Coppari R. Hypothalamic neurones governing glucose homeostasis. J Neuroendocrinol. 2015;27(6):399-405.

18. Berglund ED, et al. Direct leptin action on POMC neurons regulates glucose homeostasis and hepatic insulin sensitivity in mice J Clin Invest. 2012;122(3):1000-1009.

19. Hill JW, et al. Direct insulin and leptin action on pro-opiomelanocortin neurons is required for normal glucose homeostasis and fertility. Cell Metab. 2010;11(4):286-297.

20. Hill JW, et al. Phosphatidyl inositol 3-kinase signaling in hypothalamic proopiomelanocortin neurons contributes to the regulation of glucose homeostasis. Endocrinology. 2009;150(11):4874-4882.

21. Huo L, et al. Leptin-dependent control of glucose balance and locomotor activity by POMC neurons. Cell Metab. 2009;9(6):537-547.

22. Nohara K, et al. Early-life exposure to testosterone programs the hypothalamic melanocortin system. Endocrinology. 2011;152(4):1661-1669.

23. Nohara K, Laque A, Allard C, Münzberg H, Mauvais-Jarvis F. Central mechanisms of adiposity in adult female mice with androgen excess. Obesity (Silver Spring). 2014;22(6):1477-1484.

24. Navarro G, Allard C, Xu W, Mauvais-Jarvis F. The role of androgens in metabolism, obesity, and diabetes in males and females. Obesity (Silver Spring). 2015;23(4):713-719.

25. Morford JJ, Wu S, Mauvais-Jarvis F. The impact of androgen actions in neurons on metabolic health and disease. Mol Cell Endocrinol. 2018;465:92-102.

26. Polonsky KS. Lilly Lecture 1994. The beta-cell in diabetes: from molecular genetics to clinical research. Diabetes. 1995;44(6):705-717

27. Weyer C, Bogardus C, Mott DM, Pratley RE. The natural history of insulin secretory dysfunction and insulin resistance in the pathogenesis of type 2 diabetes mellitus. J Clin Invest. 1999;104(6):787-794.

28. O'Meara NM, et al. Defects in beta-cell function in functional ovarian hyperandrogenism. J Clin Endocrinol Metab. 1993;76(5):1241-1247.

29. Dunaif A, Finegood DT. Beta-cell dysfunction independent of obesity and glucose intolerance in the polycystic ovary syndrome. J Clin Endocrinol Metab. 1996;81(3):942-947.

30. Holte J, Bergh T, Berne C, Berglund L, Lithell H. Enhanced early insulin response to glucose in relation to insulin resistance in women with polycystic ovary syndrome and normal glucose tolerance. J Clin Endocrinol Metab. 1994;78(5):1052-1058.

31. Goodarzi MO, Erickson S, Port SC, Jennrich RI, Korenman SG. beta-Cell function: a key pathological determinant in polycystic ovary syndrome. J Clin Endocrinol Metab. 2005;90(1):310-315.

32. Navarro G, et al. Extranuclear actions of the androgen receptor enhance glucose-stimulated insulin secretion in the male. Cell Metab. 2016;23(5):837-851.

33. Lee JY, Ristow M, Lin X, White MF, Magnuson MA, Hennighausen L. RIP-Cre revisited, evidence for impairments of pancreatic beta-cell function. J Biol Chem. 2006;281(5):2649-2653.

34. Wicksteed B, et al. Conditional gene targeting in mouse pancreatic ß-cells: analysis of ectopic Cre transgene expression in the brain. Diabetes. 2010;59(12):3090-3098.

35. Oropeza D, et al. Phenotypic characterization of MIP-CreERT1Lphi mice with transgene-driven islet expression of human growth hormone. Diabetes. 2015;64(11):3798-3807.

36. Lacy PE, Walker MM, Fink CJ. Perifusion of isolated rat islets in vitro. Participation of the microtubular system in the biphasic release of insulin. Diabetes. 1972;21(10):987-998.

37. Jones PM, Stutchfield J, Howell SL. Effects of Ca2+ and a phorbol ester on insulin secretion from islets of Langerhans permeabilised by high-voltage discharge. FEBS Lett. 1985;191(1):102-106.

38. Alejandro EU, et al. Overexpression of kinase-dead mTOR impairs glucose homeostasis by regulating insulin secretion and not B-cell mass. Diabetes. 2017;66(8):2150-2162.

39. Xiang X, Saha AK, Wen R, Ruderman NB, Luo Z. AMP-activated protein kinase activators can inhibit the growth of prostate cancer cells by multiple mechanisms. Biochem Biophys Res Commun. 2004;321(1):161-167.

40. Xu Y, Chen SY, Ross KN, Balk SP. Androgens induce prostate cancer cell proliferation through mammalian target of rapamycin activation and post-transcriptional increases in cyclin D proteins. Cancer Res. 2006;66(15):7783-7792.

41. Recchia AG, et al. A cross-talk between the androgen receptor and the epidermal growth factor receptor leads to p38MAPK-dependent activation of mTOR and cyclinD1 expression in prostate and lung cancer cells. Int J Biochem Cell Biol. 2009;41(3):603-614.

42. Liu S, Navarro G, Mauvais-Jarvis F. Androgen excess produces systemic oxidative stress and predisposes to beta-cell failure in female mice. PLoS One. 2010;5(6):e11302.

43. Gille L, et al. Generation of hydroxyl radicals mediated by streptozotocin in pancreatic islets of mice in vitro. Pharmacol Toxicol. 2002;90(6):317-326.

44. Friesen NT, Büchau AS, Schott-Ohly P, Lgssiar A, Gleichmann H. Generation of hydrogen peroxide and failure of antioxidative responses in pancreatic islets of male C57BL/6 mice are associated with diabetes induced by multiple low doses of streptozotocin. Diabetologia. 2004;47(4):676-685.

45. Le May C, et al. Estrogens protect pancreatic beta-cells from apoptosis and prevent insulin-deficient diabetes mellitus in mice. Proc Natl Acad Sci USA. 2006;103(24):9232-9237. 
46. Kilic G, et al. The islet estrogen receptor- $\alpha$ is induced by hyperglycemia and protects against oxidative stress-induced insulin-deficient diabetes. PLoS One. 2014;9(2):e87941.

47. Andrisse S, et al. Low-dose dihydrotestosterone drives metabolic dysfunction via cytosolic and nuclear hepatic androgen receptor mechanisms. Endocrinology. 2017;158(3):531-544.

48. Mauvais-Jarvis F, Arnold AP, Reue K. A guide for the design of pre-clinical studies on sex differences in metabolism. Cell Metab. 2017;25(6):1216-1230.

49. Dunaif A, Segal KR, Futterweit W, Dobrjansky A. Profound peripheral insulin resistance, independent of obesity, in polycystic ovary syndrome. Diabetes. 1989;38(9):1165-1174.

50. Thorens B, Tarussio D, Maestro MA, Rovira M, Heikkilä E, Ferrer J. Ins1(Cre) knock-in mice for beta cell-specific gene recombination. Diabetologia. 2015;58(3):558-565.

51. Johnston NR, et al. Beta cell hubs dictate pancreatic islet responses to glucose. Cell Metab. 2016;24(3):389-401.

52. Hodson DJ, et al. ADCY5 couples glucose to insulin secretion in human islets. Diabetes. 2014;63(9):3009-3021.

53. Gao H, Molinas AJR, Miyata K, Qiao X, Zsombok A. Overactivity of liver-related neurons in the paraventricular nucleus of the hypothalamus: electrophysiological findings in db/db mice. J Neurosci. 2017;37(46):11140-11150. 